AG:DP/AFG/94/002

Field Document 1

FOOD AND AGRICULTURE ORGANISATION

OF THE UNITED NATIONS

\title{
Integrated crop and food production in Afghanistan
}

An account of the achievements of the AFG/94/002 programme 1995-1997

and opportunities for 1997-1999

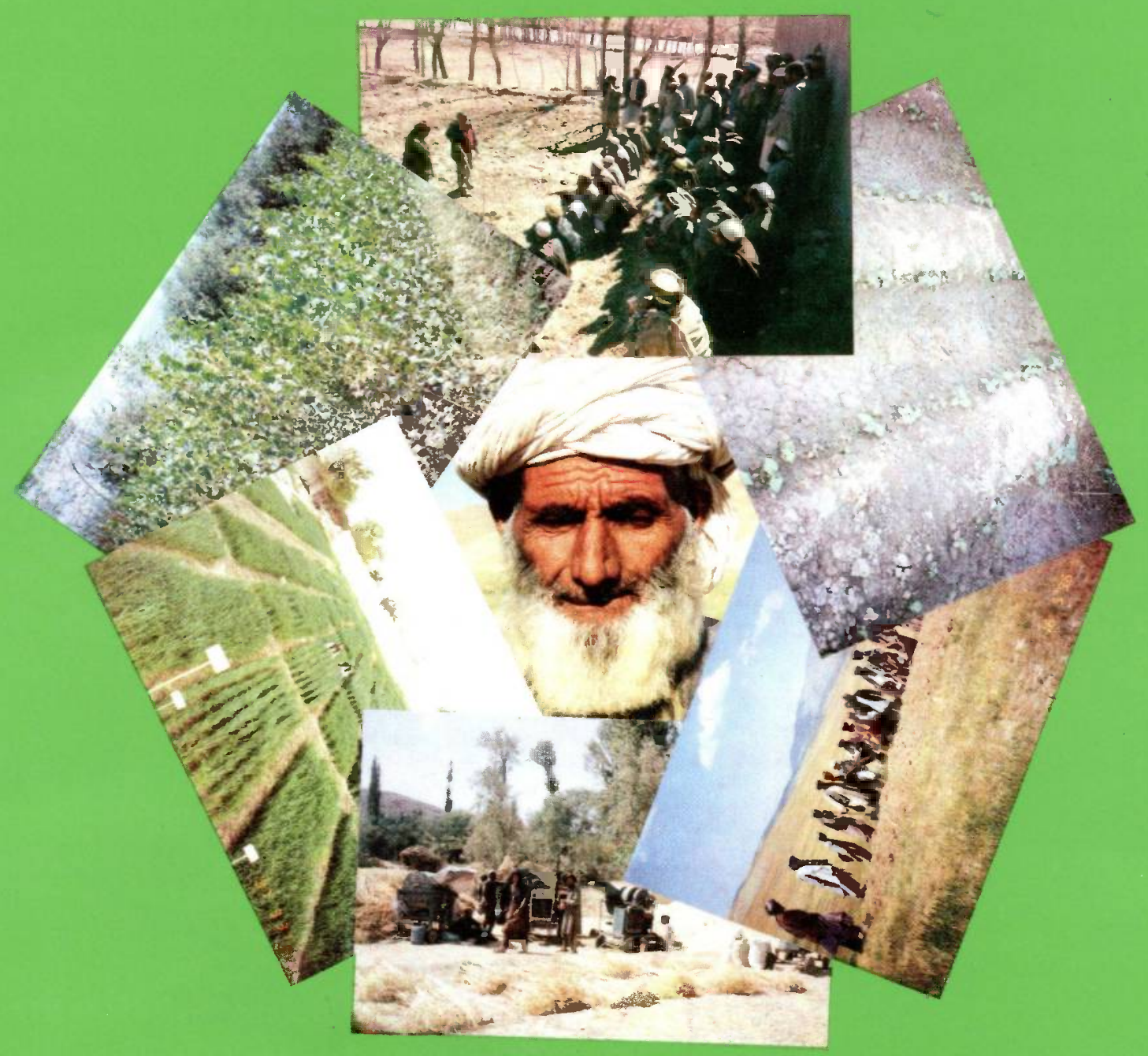

FAO AFG/94/002, Islamabad 


\section{DISCLAIMER}

The designations employed and the presentation of the materials in this publication do not imply the expression of any opinion on the part of FAO or UNDP concerning the legal status of any country, territory, city or area or of its authorities, or concerning the delimitations of its frontiers or boundaries.

The opinions expressed in this publication are those of the authors alone and do not imply any opinion whatsoever on the part of FAO or UNDP. 

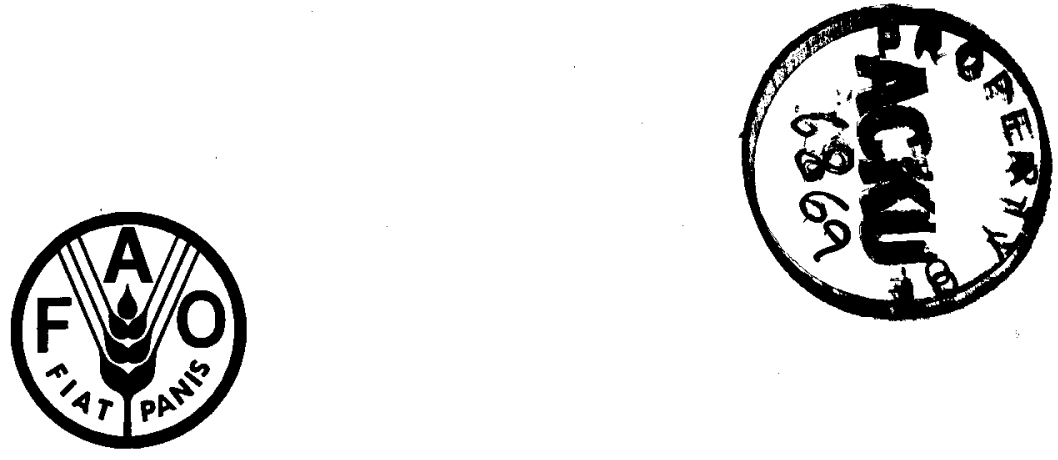

AG:DP/AFG/94/002

Field Document 1

\section{FOOD AND AGRICULTURE ORGANISATION}

OF THE UNITED NATIONS

\section{Integrated crop and food production in Afghanistan}

An account of the achievements of the AFG/94/002 programme 1995-1997

and opportunities for 1997-1999

FAO AFG/94/002, Islamabad 


\section{ACKNOWLEDGMENTS}

The development of agricultural production and food security in Afghanistan is clearly considered a priority by the international donor community which has given generous additional support to different elements of the AFG/94/002 programme during the period 1995-1997. The following contributions are gratefully acknowledged:

European Union (US\$4,370,000)

Government of Switzerland (US\$257,460)

Royal Norwegian Government 10 Rubbhalls (US\$228,333)

WFP 9687 tonnes food wheat (US $\$ 3,005,000$ )

UNDCP (US\$381,200)

UNHCR (US\$28,000).

The Government of Sweden (SIDA) for funding the crop improvement element of this programme with US $\$ 1,540,000$.

The Government of the Peoples Democratic Republic of China and the Government of Thailand for their donations of silkworm eggs.

UNDP for providing the bulk of funding for the AFG/94/002 programme.

UNOCHA and the designated, field and area security officers who assist FAO to travel and do its job in a secure and trouble free manner and the staff of other UN agencies that work in the various duty stations in Afghanistan for their daily co-operation and support.

The implementing partners: NGOs, parastatals, PPQD and farmers who have been involved with the programmes and whose hospitality in Afghanistan assists FAO staff to do their job.

FAO headquarters staff in Rome and all visiting consultants and backstoppers who act as technical support and sources of inspiration for technical staff employed by the programme.

All FAO, AFG/94/002 and other UN employees who have contributed to the implementation and success of these programmes and the production of this document.

This document was compiled, written and edited by Barry Stride, STA Plant Protection, from contributions submitted by Senior Technical Advisers. 
Acknowledgments (i)

Contents 1

Foreword 3

INTEGRATED CROP AND FOOD PRODUCTION IN AFGHANISTAN AFG/94/002

INTRODUCTION 5

Background

Co-operation with other UN Agencies

Programme implementation, monitoring and impact assessment

Integrated activities, Farmer Field Schools, Sustainable Programmes and Input

Supply

The potential of developed apiculture and sericulture industries

PROGRAMME ACHIEVEMENTS IN 1995-97 AND OPPORTUNITIES FOR 1997-99

SEED PRODUCTION 9

Implementation strategy

Food for seed production schemes

Producers of improved seed

Production of quality declared seed and its distribution with fertiliser

Opportunities for the 1997-99 programme

CROP IMPROVEMENT 14

Results of testing new varieties of Wheat

Results of testing new warieties of Barley

Results of testing new varieties of Rice

Results of testing new varieties of Maize

Selection of disease resistance amongst local varieties; preserving a genetic resource

Opportunities for the 1997-99 programme

HORTICULTURE

20

Fruit crops - Nurseries

Fruit crops - Orchards

Dried Fruits

Vegetables

Planning the development of horticulture

PLANT PROTECTION 28

Plague Insect Control

Integrated Pest Management

Powdery Mildew of Grapes and Smut Disease of Wheat

Melon fly

Weed Control

Environmental work

Opportunities for the 1997-99 programme

APICULTURE 33

Beekeeping in the present day and opportunities for the 1997-99 programme

SERICULTURE

33

Opportunities for the 1997-99 programme

PROGRAMME PROPOSALS REQUIRING ADDITIONAL FUNDING 
Plate 1

Winter in Takhar
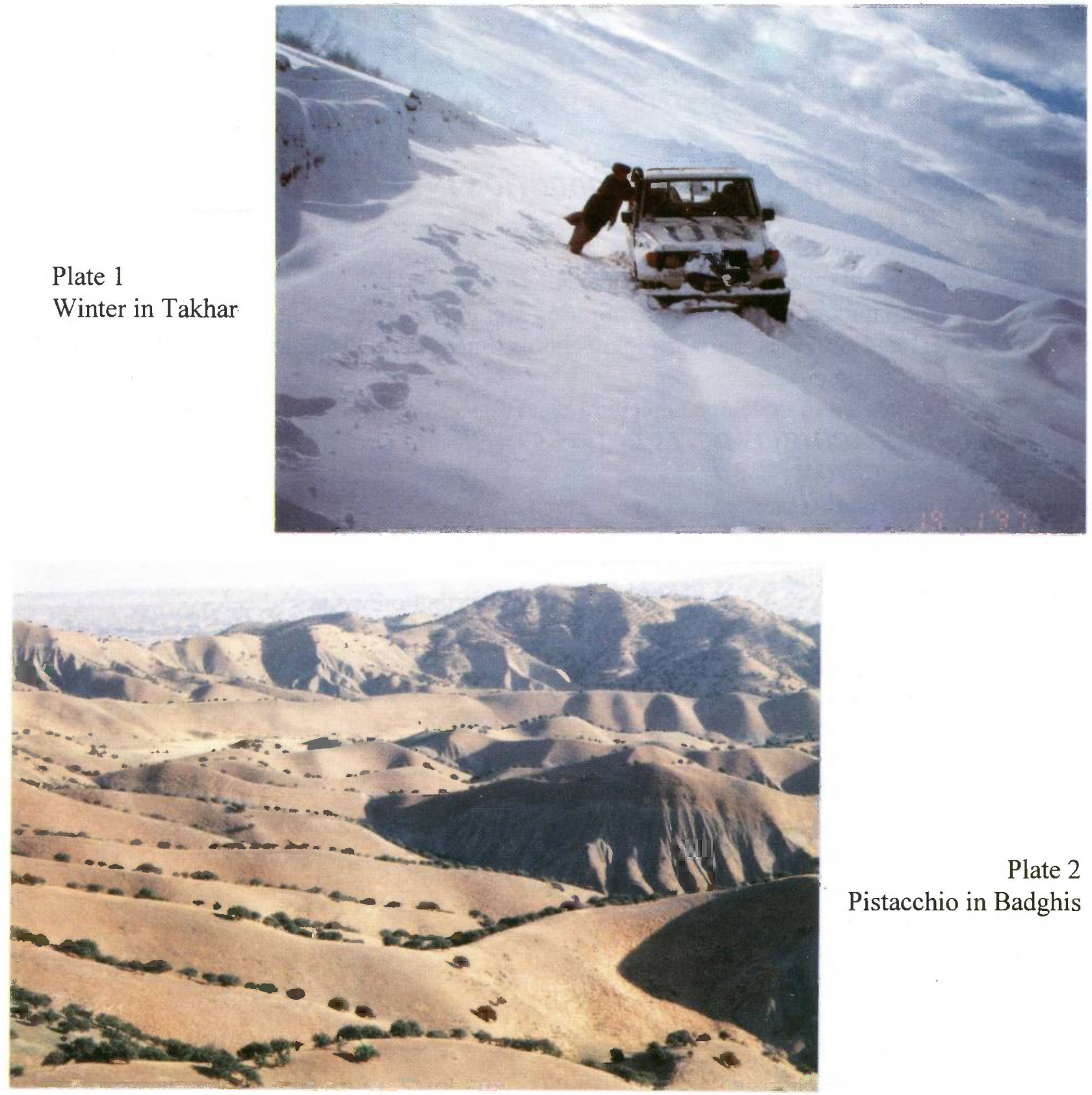

Plate 2

Pistacchio in Badghis

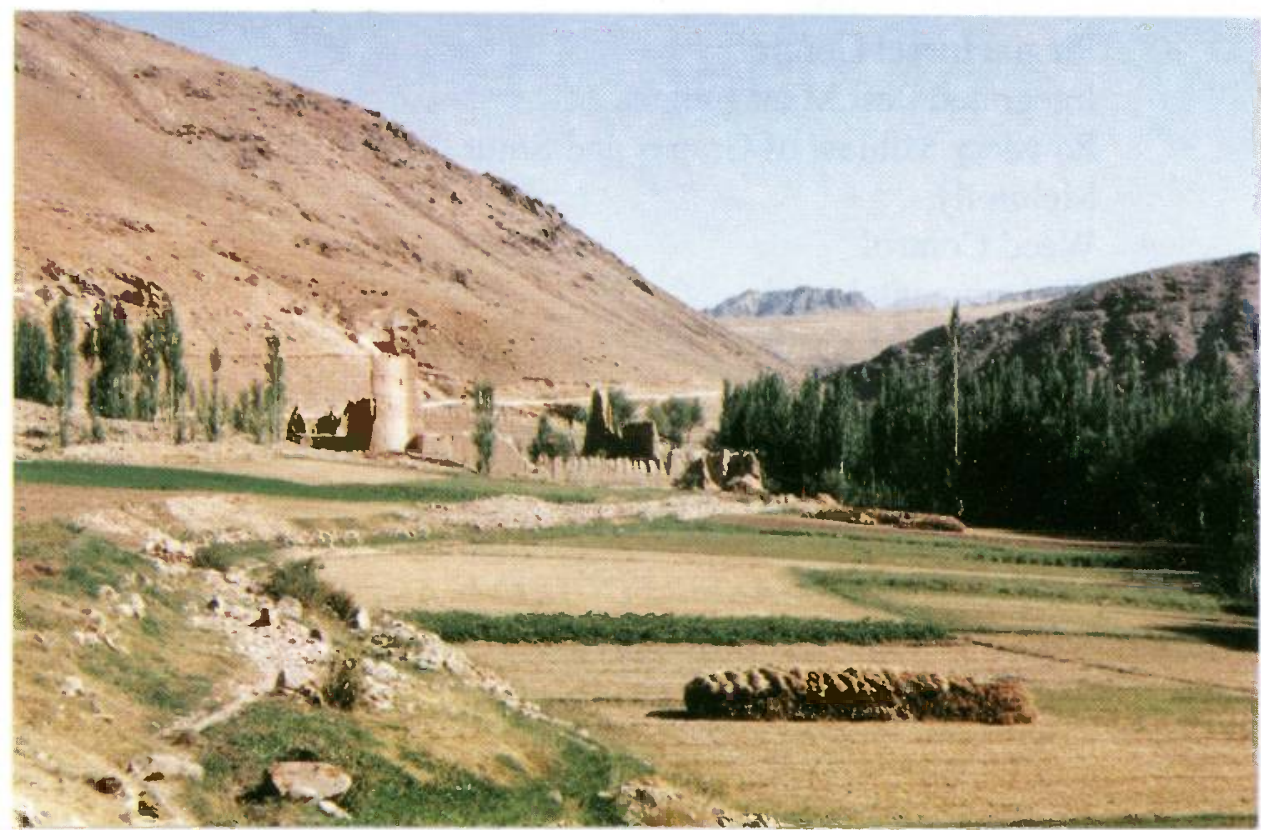




\section{FOREWORD}

Afghanistan is a country with an agrarian economy in which $85 \%$ of the population make their livelihood. This Document reports the achievements of the FAO/UNDP Integrated Crop and Food Production Programme in Afghanistan, AFG/94/002, which assists farming communities to develop their industry.

The Document is intended to show, that in spite of all the headline grabbing political and military troubles in Afghanistan, solid achievements can be made and opportunities exist for setting the country's agricultural sector on a path towards sustainable development.

The main focus of this Document are the achievements of the Programme from 1995 to 1997. Sustainable agricultural development has a much longer time frame and many more facets. Some possible interventions that need attention soon are outlined in an annexure.

For a long time to come agricultural production will have to serve as the foundation for rebuilding the economy of the country. Meanwhile, there are other needs to be met: emergency assistance to the most deprived and the rehabilitation and rebuilding of rural and urban infrastructures. By integrating humanitarian and rehabilitation assistance with solid, commercially viable and sustainable agricultural development programmes the groundwork could be laid for building a civilian society at peace in Afghanistan.

Hans C Brink

Programme Manager AFG/94/002 
Plate 4

Training farmers Logar
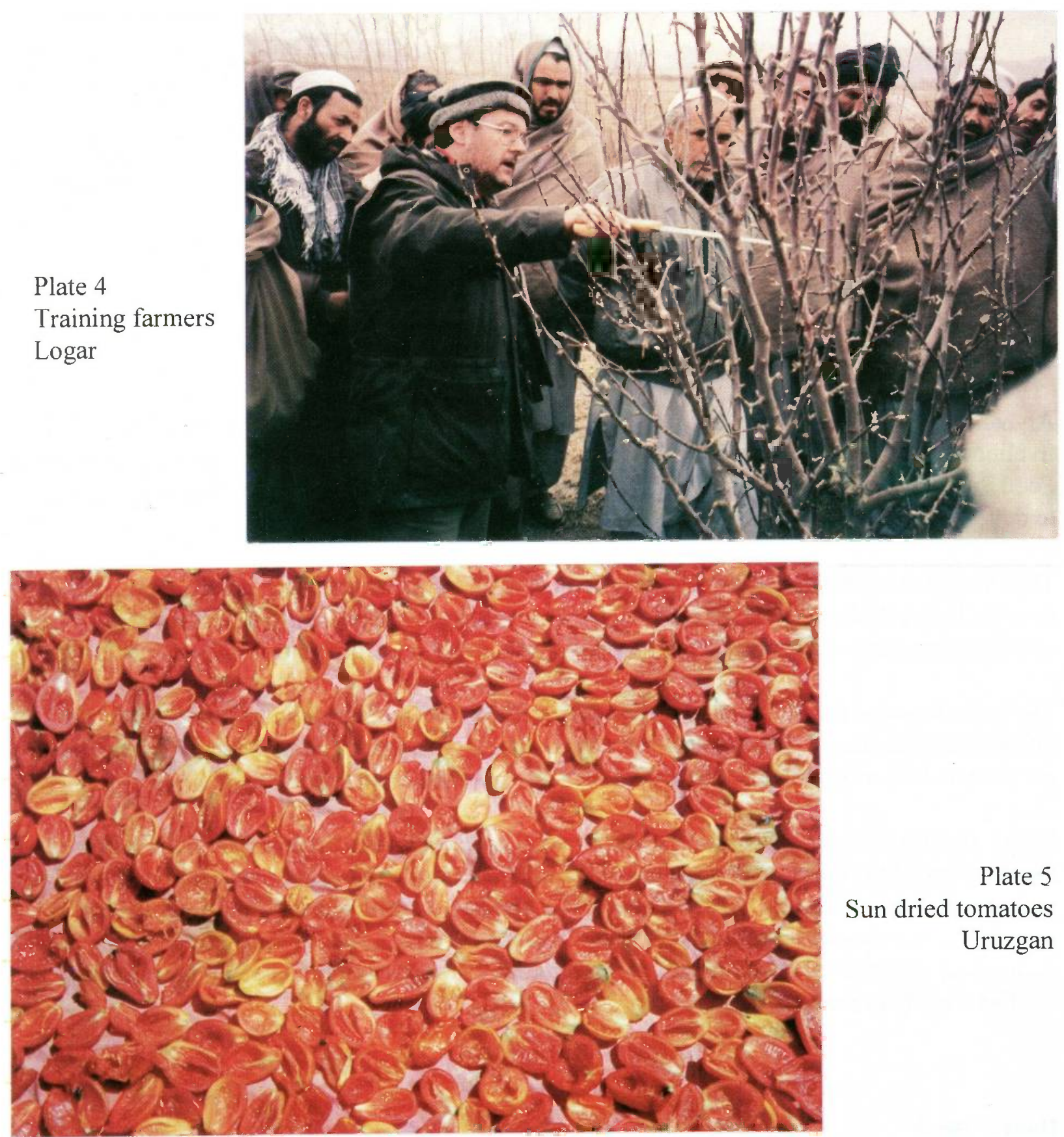

Plate 5

Sun dried tomatoes

Uruzgan

Plate 6

Preparation of apricots for curing with sulphur Ghazni

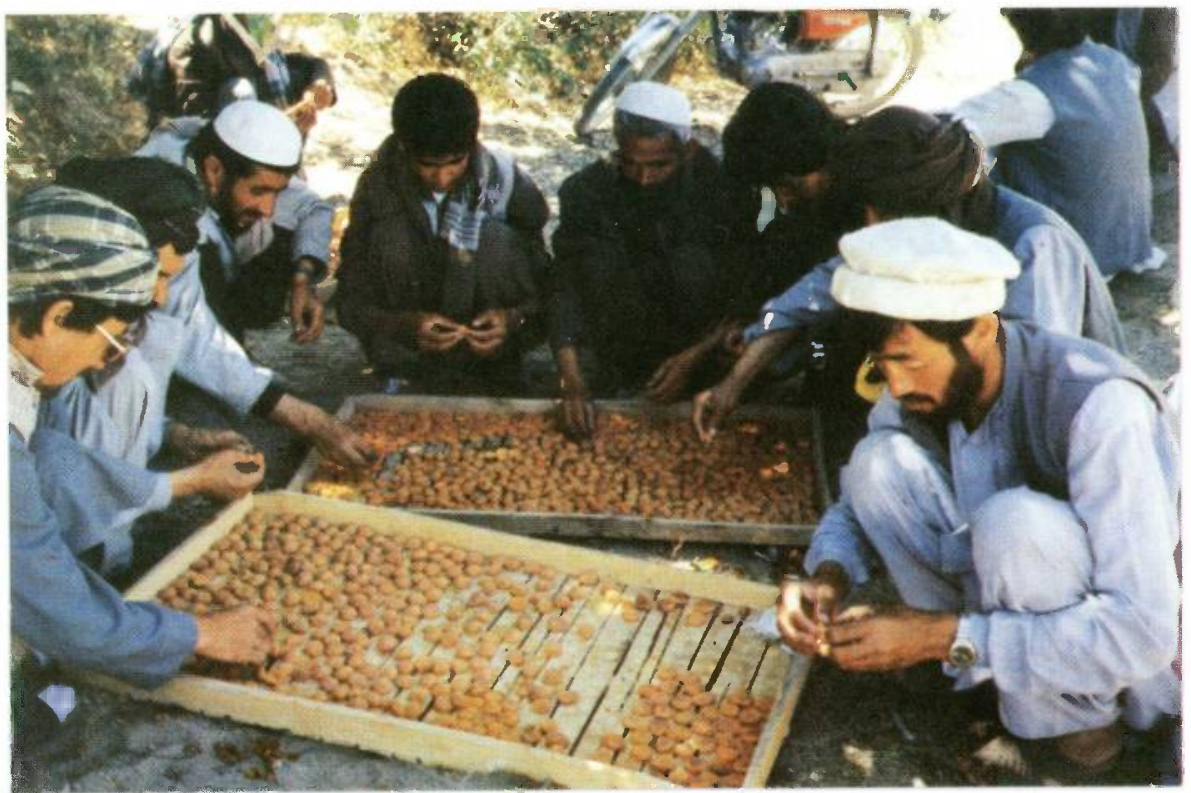




\section{INTRODUCTION}

This booklet is a brief record of the technical achievements of the FAO crops programme in the period April, 1995-April, 1997 and a look at the opportunities for further development in the next phase 1997-1999. A glossary of acronyms used in the text is inside the back cover.

\section{Background}

Agriculture is an integrated activity and AFG/94/002 is the integrated crop production programme for all Afghanistan. There are six offices: Taloqan; Jalalabad; Ghazni; Qandahar; Herat and Mazari-Sharif. Inaugurated on April 1st, 1995, under one manager and four senior technical advisers, it incorporates the activities of several separate earlier programmes involving: agronomy; seed production; crop improvement; horticulture and plant protection and with an active interest in the development of apiculture and sericulture. The programme functions as an extension service supporting the implementation of agricultural development projects to attain sustainable long term food security based on commercial lines.

\section{Co-operation with other UN Agencies}

The FAO programme has found a number of opportunities to co-operate with other UN agencies in joint undertakings: with WFP in food-for-seed in which grain is given in exchange for seed produced by contracted farmers; food-for-rent in which grain is given in lieu of lost wheat production during the two year period in which farmers establishing private nurseries receive assistance and food-for-work in which grain is supplied in lieu of wages, for example, to labourers employed in ridding the environment of stockpiles of BHC dust. UNHCR has implemented seed production activities as part of the campaign to support returnees and UNDCP has introduced the use of improved wheat seed in its programmes aimed at reducing the area planted with poppy.

\section{Programme implementation, monitoring and impact assessment}

The programme has been very much involved with the transfer of skills and technical information to farmers: changing farmers attitudes to the perception of what a problem is and in how to solve it. Participatory methods introduced into the training and extension process encourage farmers to be independent and confident by involving them in the decision making process and empowering them to take responsibility for identifying and solving the problems that occur in their fields. Learning by doing and seeing in demonstrations gives farmers an opportunity to decide for themselves if the new method is better than the old.

The programme is generally confined to the major areas of production. It is not possible to reach the most isolated villages, but it is possible for the remotest and poorest to reach the programme! Project implementation introduces in a step by step approach technology appropriate for an extensive relatively low input agricultural system. The adoption of more sophisticated approaches depends on the reliable import of the recommended inputs.

Programmes are implemented by various methods, for example: through NGOs; parastatals; by co-operation with other UN agencies and directly by programme personnel through the community. In general, the sub-projects are planned by the senior technical staff and monitored by NPPPs and the STAs.

Whereas the true value of the programme is its impact on farm income, the adoption of new technology by farmers and the alleviation of poverty or hunger, the most frequently quoted figures used as measures of impact are those obtained most easily, that is, measures of output: number of farmers trained, the number of tonnes produced etc. Assessment of the impact of programme activities on farm income is difficult to evaluate: there is very little good baseline information on 
Plate 7

Rainfed Wheat

Faryab
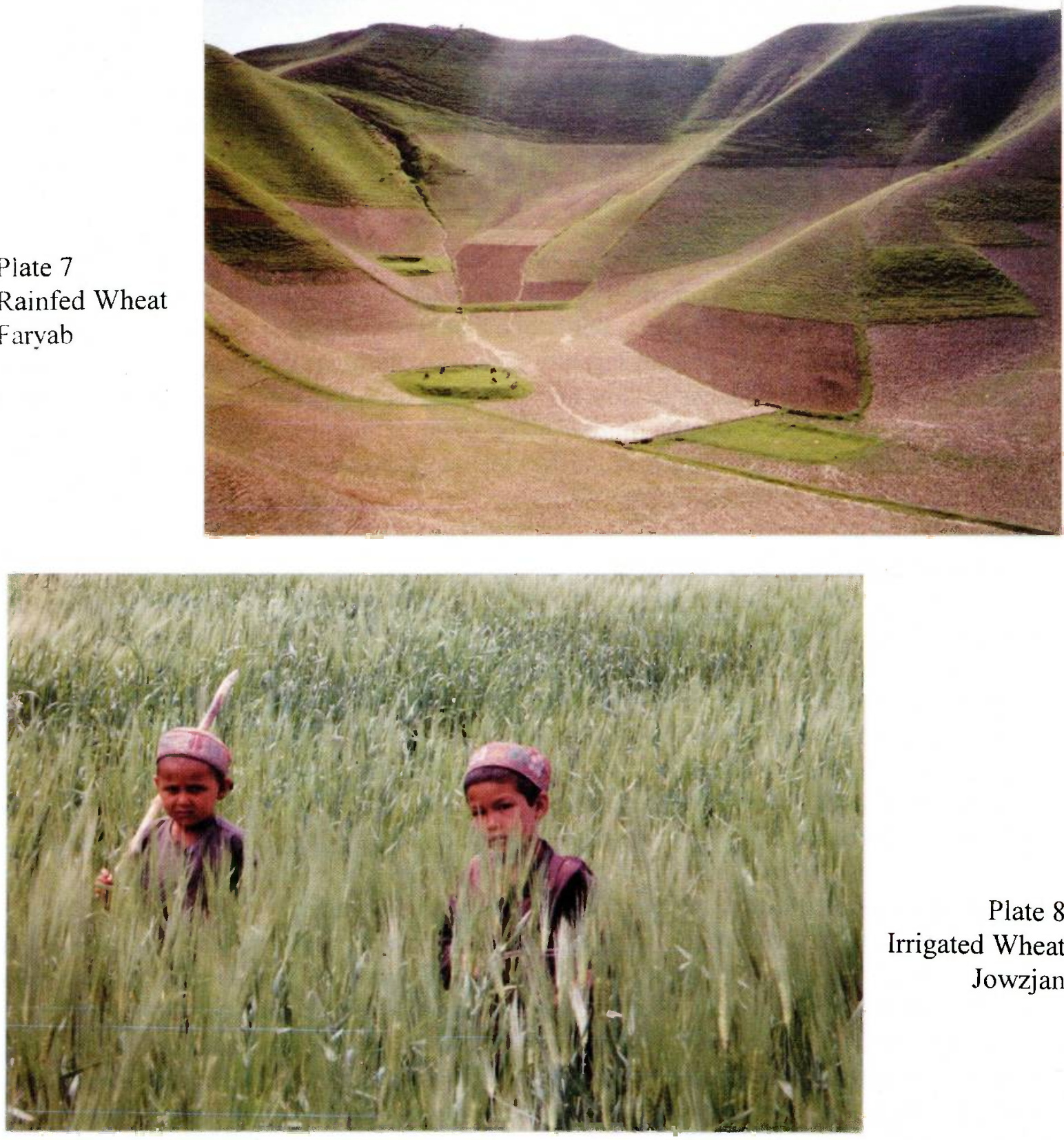

Plate 8

Irrigated Wheat

Jowzjan

Plate 9

Wheat Harvest

Badghis

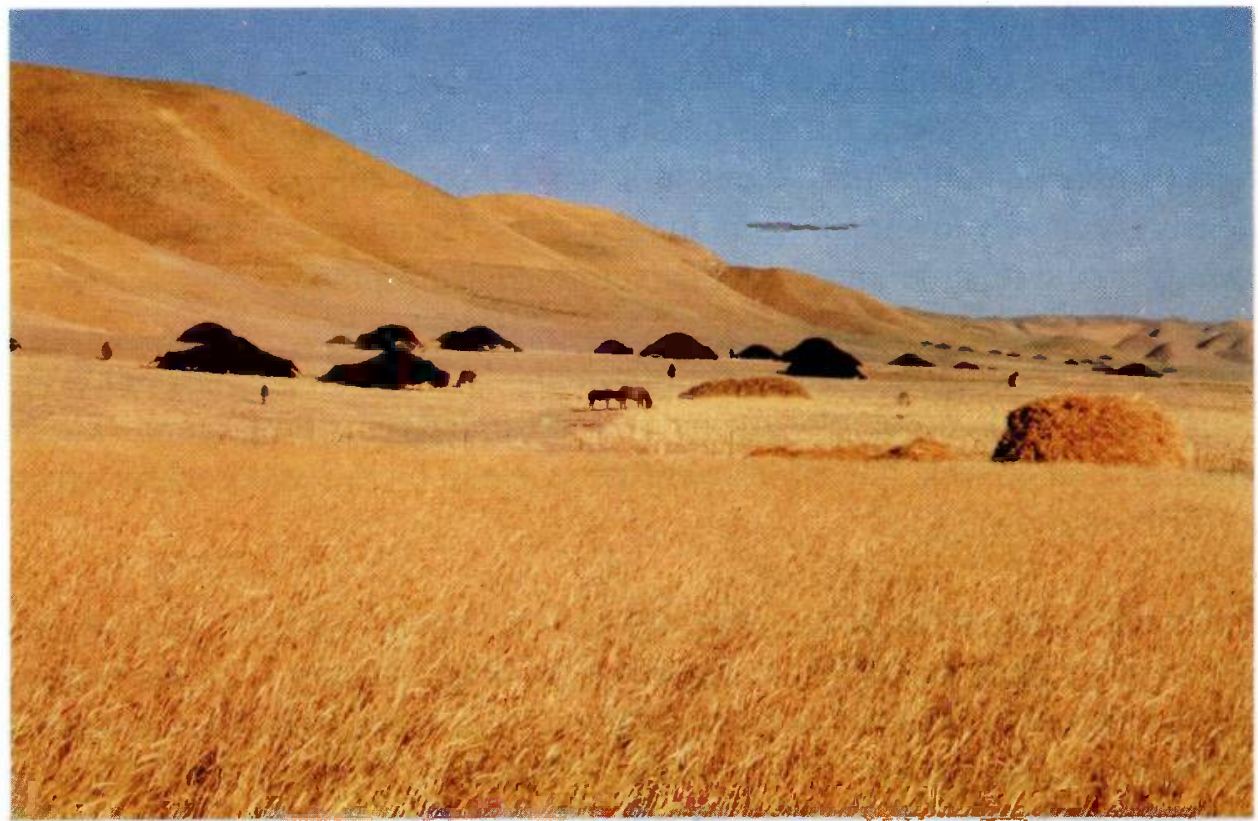




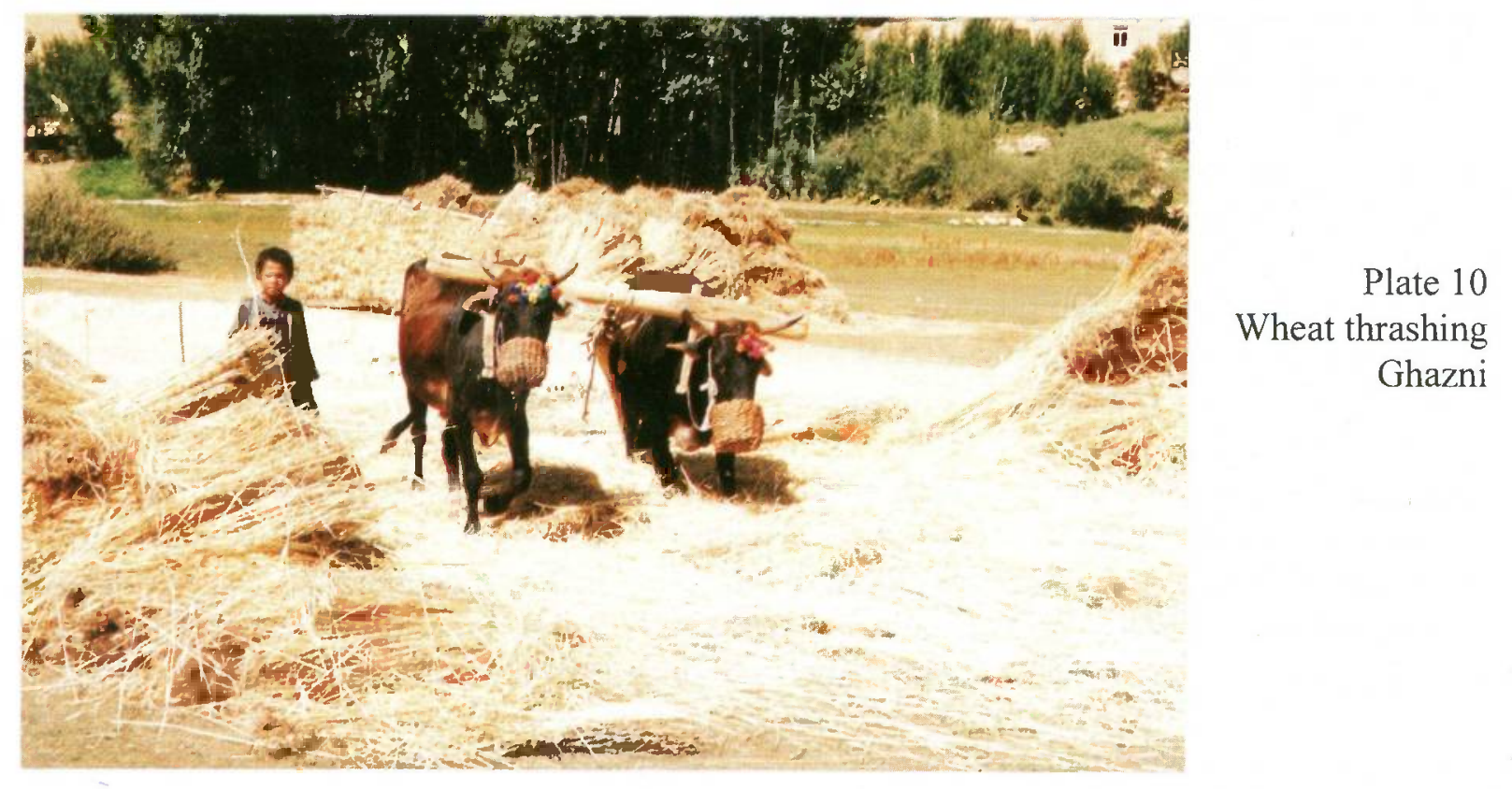

Winnowed Wheat Ghazni
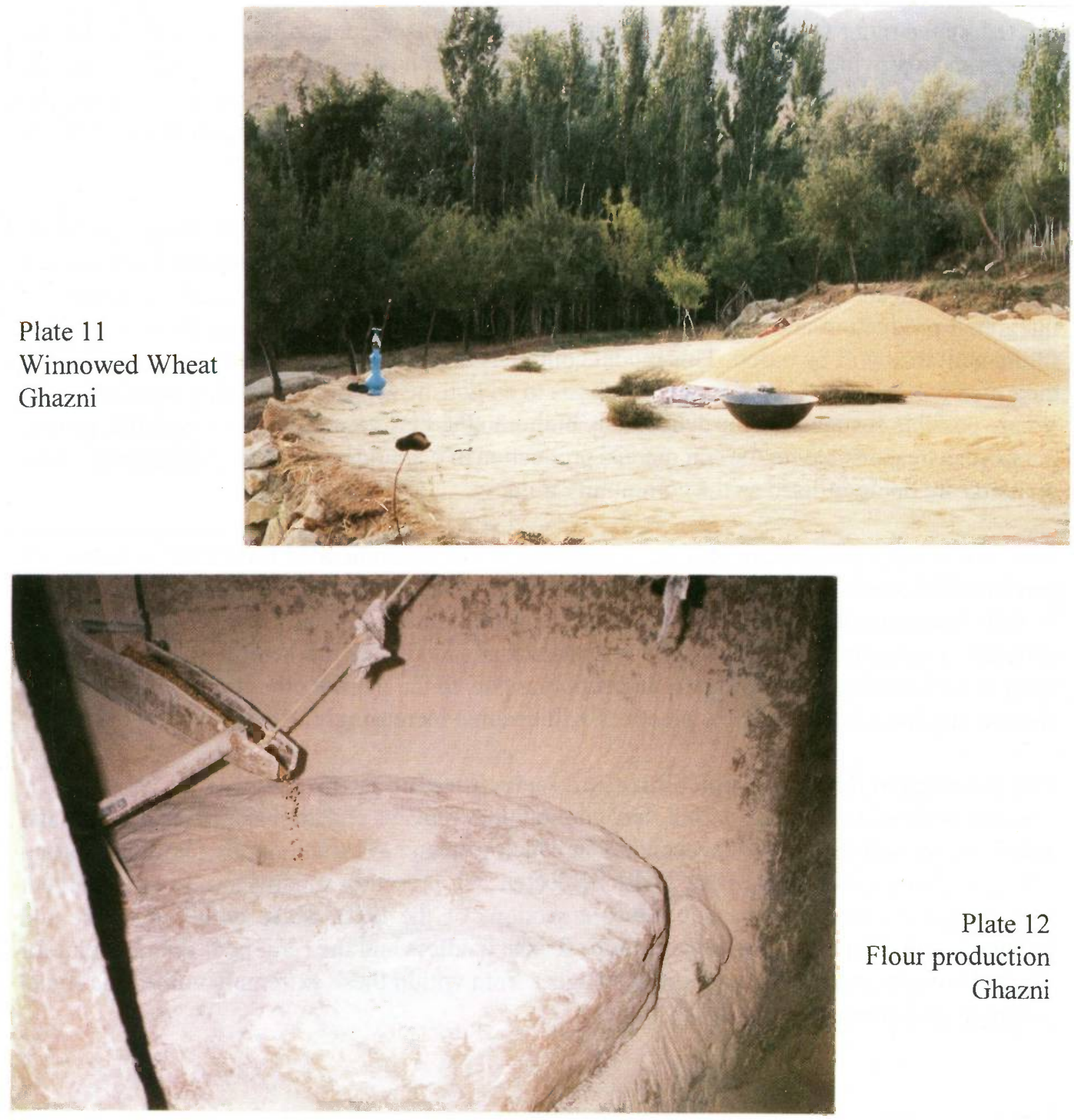

Plate 12

Flour production

Ghazni 
farm income and no simple method to measure it. Impact assessment of the programme should be improved in the new phase, but requires specialist socio-economic assistance.

Integrated activities, Farmers Field Schools, Sustainable Programmes and Input Supply Within the different elements of the programme there are many opportunities for integrated activities, for example, the production of improved seed varieties by the crop improvement section and their multiplication into quantities that satisfy the market demand by the seed production component, similarly in the production of improved vegetable seeds by these two sections plus the integration of the horticultural component.

In the fifteen eastern and southern provinces, from Kunar in the north to Helmand in the south, an extension system based on farmers field schools (FFS) is being established in some eighty districts considered as major areas of production of orchard crops and vineyards. The programme is being implemented by four international NGOs. The FFS system has the potential to integrate a range of activities from the different elements of the programme into one extension system.

Under the FFS system technical information is transferred at village level to farmers by demonstrations and training facilitated by a community trainer (a literate and innovative farmer elected by the other farmers within the community) who is supported by a network of district trainers and a provincial supervisor. The community trainer having been selected and trained acts as a focus for communication between the farmers and the FAO programme enabling the AFG/94/002 programme to send technical messages and prepared extension material to all communities and farmers willing to participate in the process.

In 1996 the FFS system was established to transfer technical advice and training to farmers concerning integrated pest management (IPM), but in 1997, through the integrated activities of the horticulture and plant protection elements, have been developed into an extension system for integrated production and protection (IPP) which is a constantly developing model on which future activities will be based. This model continues to empower farmers to identify and solve their own problems, but gives greater emphasis to an holistic approach towards crop production. Where possible sustainability is deliberately built into the FFS programme, for example, private nurserymen responsible for the commercial production of planting material for Afghanistan's new orchards are being utilised as the community trainers.

Sustainable programmes can only be established if the recommended inputs are available for purchase by farmers in the bazaars. The programme is creating a demand for recommended inputs by their demonstration in farmers fields and by training farmers in their use. In order to meet this demand an agricultural trader with shops in Qandahar and Ghazni has been supported to supply them, if he is able to reliably import and supply inputs to the market other traders will copy his success and the adoption of new practices will become increasingly widespread.

\section{The potential of developed apiculture and sericulture industries}

The economic role of women within rural communities remains underdeveloped. Sericulture and apiculture are sectors of the rural economy in which women have traditionally played important roles, but both sectors have been badly neglected, are presently rundown and require urgent rebuilding and rehabilitation (see relevant sections of the text). Since both sericulture and apiculture represent economic opportunities for the landless and the rural poor the potential for relief of poverty and the early return of refugees from within these extremely vulnerable social groups is also compromised. 


\section{SEED PRODUCTION}

Wheat is the staple crop of Afghanistan, irrigated land producing $93 \%$ of total production. Afghans consume per capita more wheat than average: about $220 \mathrm{~kg}$ per year thus the annual production requirement is estimated to be between 4.0 and 4.5 million tonnes per year. The sowing requirement for the irrigated land is estimated at 280,000 tonnes of seed per year. If all this seed is replaced over, say, seven years the annual seed replacement requirement is about 42,000 tonnes which at an average yield of 1.75 tonnes per ha is equivalent to about 24,000 ha of irrigated land devoted to seed production each year, although high yielding improved varieties will reduce this area significantly.

Traditionally Afghan farmers have produced their own seed by saving and selecting part of their harvest for the next growing season: a practice still dominant in most of the country. Crop varieties and shortage of fertilisers are frequently quoted as reasons for declining yields: most old seed varieties are low yielding and susceptible to disease.

The national agencies once responsible for agricultural research and extension have become nonfunctional or ceased to exist. In the late 1980's, as part of emergency relief FAO, funded by UNDP and other donors, implemented temporary programmes to replace disease susceptible and low yielding varieties with quality seed of improved varieties (disease resistant and high yielding) as part of a "starter package" for returning refugees. However, the success of the emergency programme was restricted by the high costs of the improved seeds (US\$600-1200 per tonne) which limited the amount of quality seed procured.

Emergency programmes cannot be continued indefinitely and any long term solution to the problem of seed availability for Afghan farmers must involve sustainable seed production inside Afghanistan where there is sufficient land, water and labour to grow the nation's seed requirement. The seed production programme has followed a strategy of establishing a network of supervised local contract seed growers in all four regions of the country.

\section{Implementation Strategy}

The objective of the programme was to set realistic goals for seed production based on local factors. Special attention was paid to increasing food production in areas suffering from chronic food deficits by the effective distribution of improved seed varieties with matching quantities of DAP and Urea fertilisers. The programme operated on a cost recovery basis, both seed and fertiliser being sold to farmers: seed at a price $10 \%$ higher than grain in the bazaars, fertiliser at about $10 \%$ less than cost price.

In on-farm seed production programmes the distribution of improved seed and fertiliser can be used effectively to promote self-sufficiency in the production of the staple food source and to reduce the cultivation of the opium poppy where farmers who are willing to destroy their poppy crop receive the improved seed and fertiliser package.

\section{Food-for-seed production schemes}

Hyper-inflation of the local currency and fear of food shortage, both common phenomena in Afghanistan in recent times, have two detrimental effects on any programme hoping to buy back seed produced under contract: firstly, it makes producers reluctant to release the seed and secondly, it makes fixing a fair purchase price for the seed produced difficult.

To overcome these problems a "food-for-seed" scheme was launched, in collaboration with WFP, in which contracted seed growing farmers were given food wheat at 1.25:1 ratio in exchange for 
Plate 13

Harvesting foundation seed of rice Baghlan

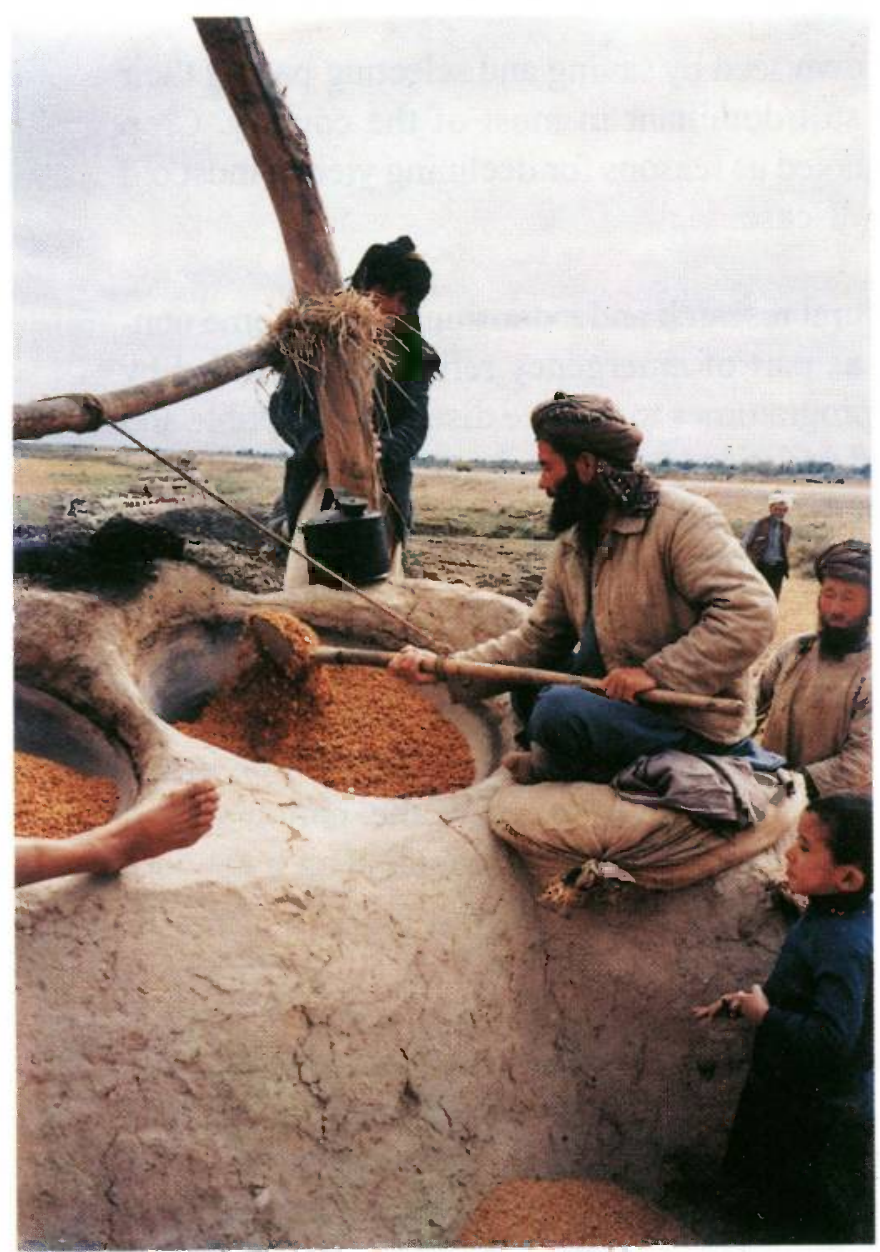

Plate 15

Seed production - 140 day cotton Balkh

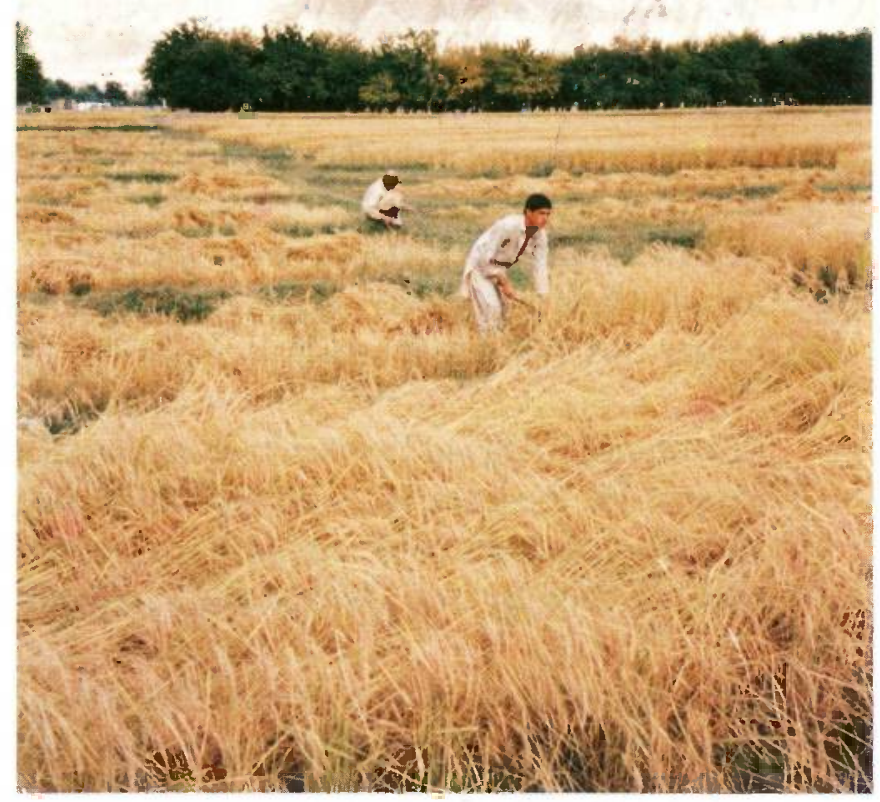

Plate 14

Par-boiling rice grain prior to storage

Baghlan

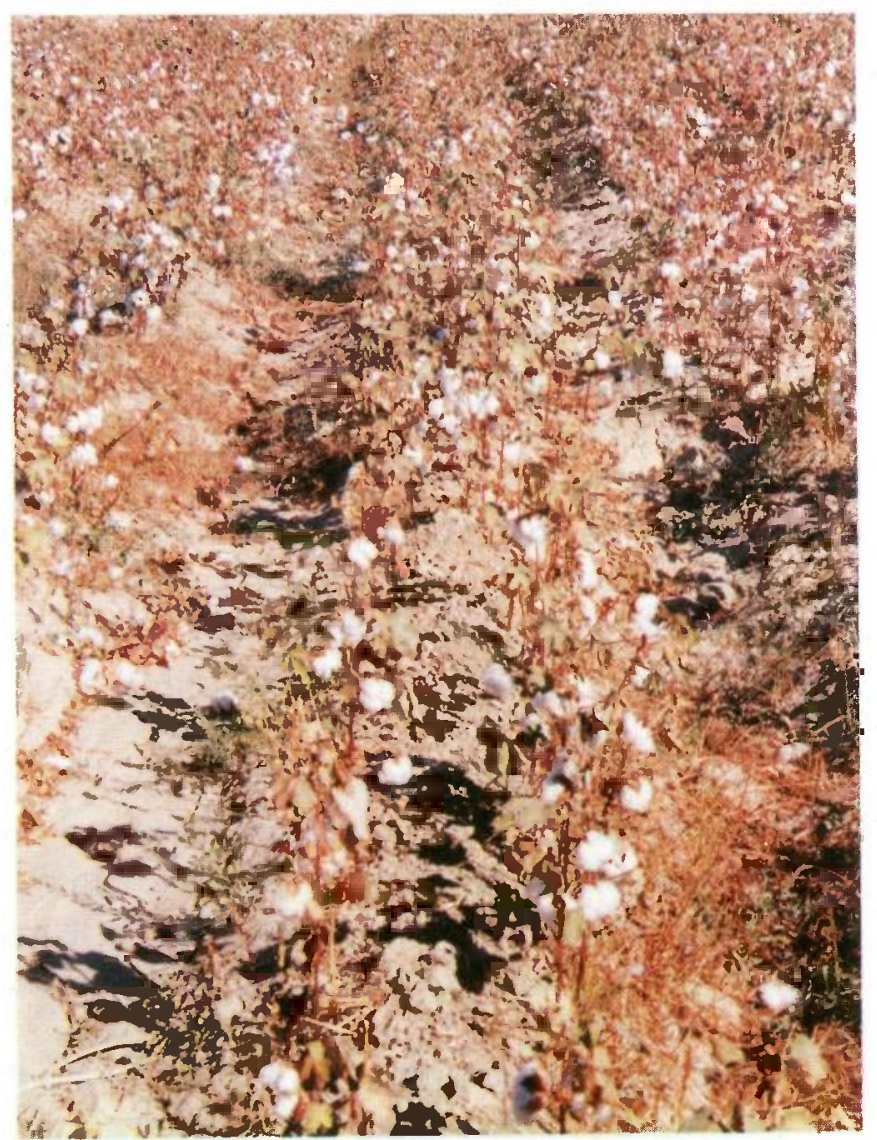




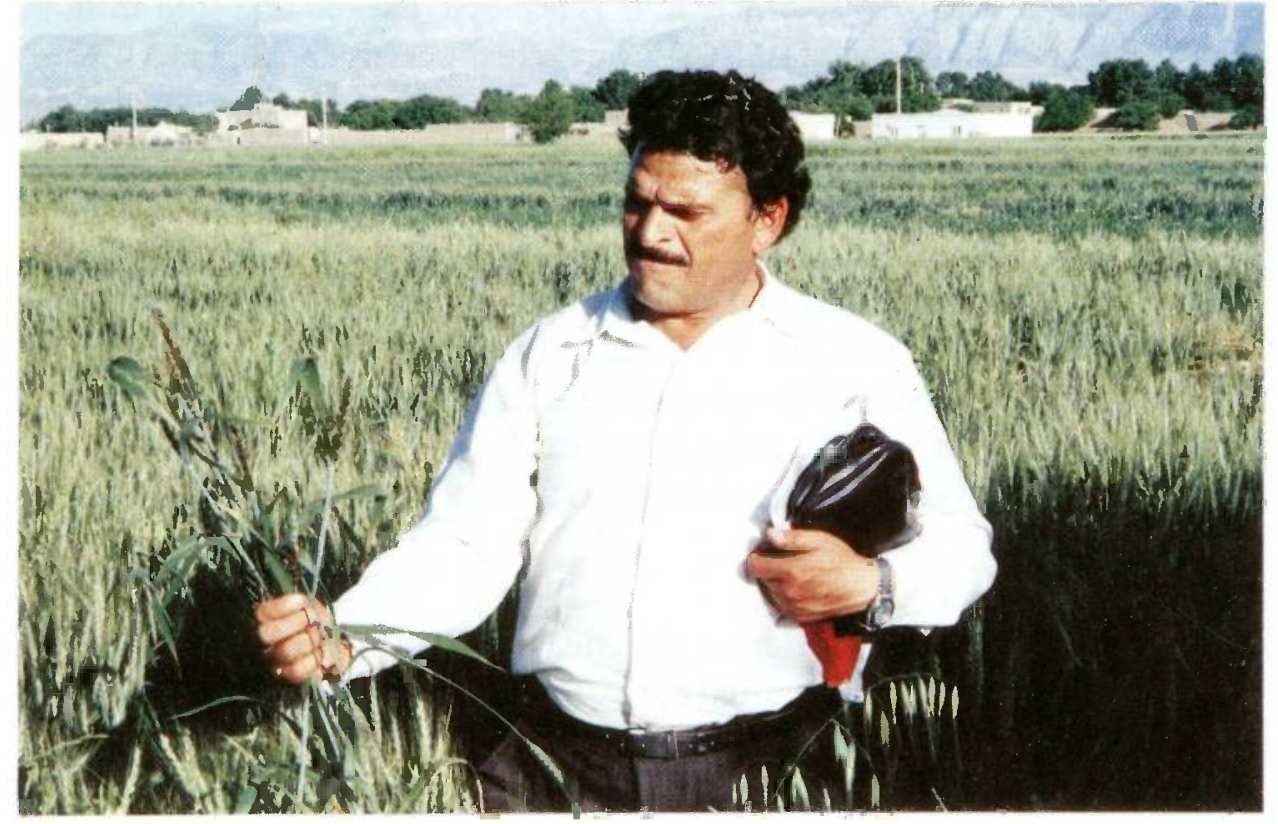

Plate 16 Smut disease of wheat Balkh
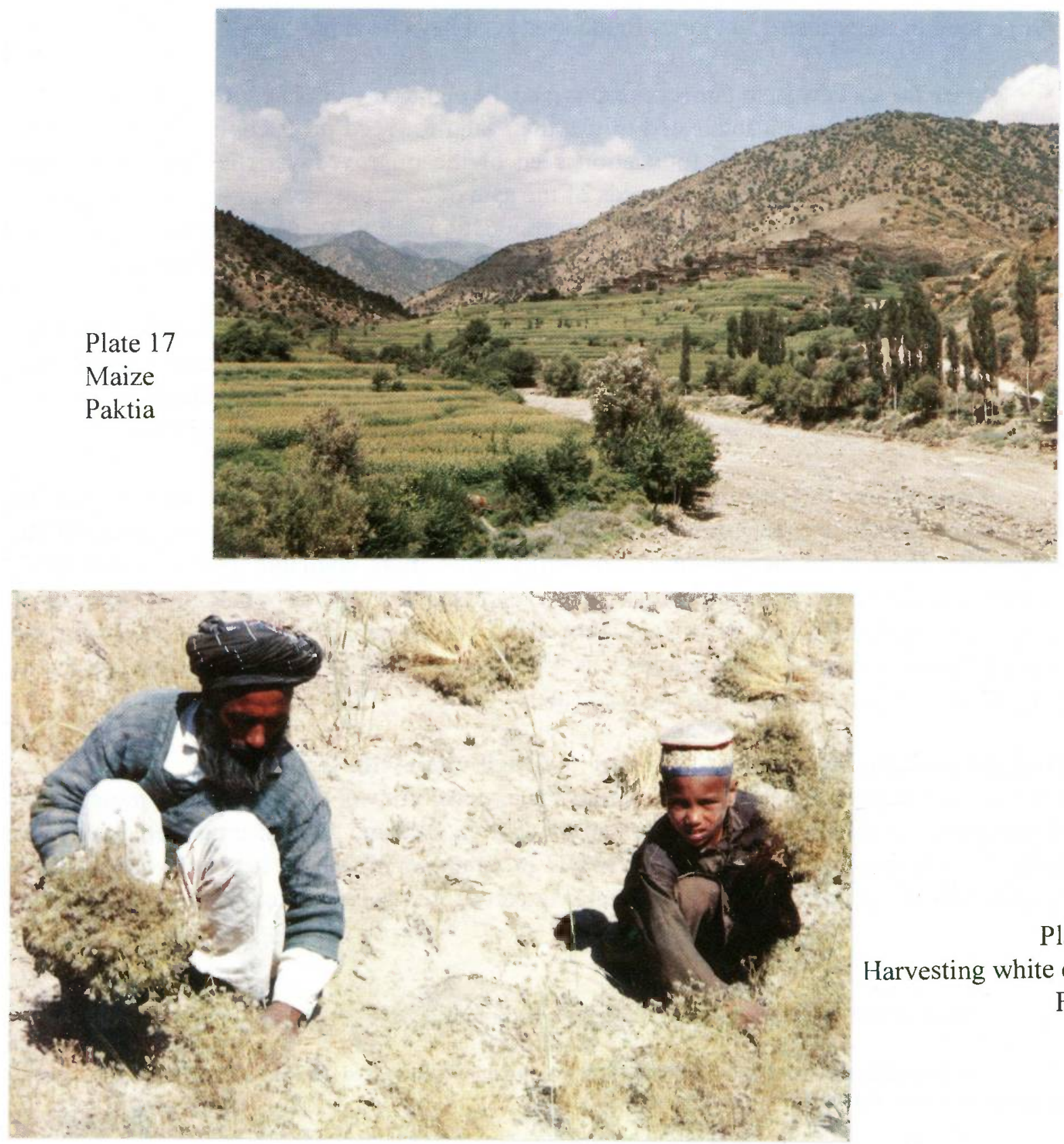

Plate 18

Harvesting white cumin

Faryab 
the wheat seed they had produced. The seed so procured is processed, packed and sold from the stores at a price determined in consultation with ACBAR. The sale proceeds are kept in a separate bank account and are used to further strengthen seed production activities after approval by the Fund Management Committee which is made up of representatives of the seed producers, the FAO programme, WFP and UNDP.

The food-for-seed scheme was launched in 1994 on an experimental basis when only 175 tonnes of food wheat was exchanged to obtain seed. The results and impact were very encouraging and as a result more than 2608 tonnes of food wheat was exchanged against declared quality seed of cereals and legumes in 1995 and 6905 tonnes in 1996 an increase of nearly $4000 \%$ in three years. In addition more than US $\$ 500,000$ has been generated from the sale of the seed produced.

\section{Producers of improved seed}

Purification and increase in quantities of the different varieties constitutes the main activities of the seed programme. Multiplication of seeds is carried out by four different implementing partners in food-for-seed schemes:

Parastatal organisation Provincial units of the ISE multiply breeder ${ }^{3}$ and foundation seed $^{2}$ under direct supervision of the project. During the last two cropping seasons (1995 and 1996) a total of more than 750 tonnes foundation seed have been produced.

State farms Few state farms have survived the eighteen years of civil war, but whenever local authorities have been interested to use their land for seed production AFG/94/002 has supplied technical information, foundation seed of the improved varieties and appropriate quantities of DAP fertiliser. The proceeds of the sale of seed produced in this way were used exclusively for further strengthening of seed production activities. More than 200 tonnes of quality declared seed ${ }^{3}$ were produced in 1996 from about 10 tonnes of foundation seed.

NGOs A number of international and national NGOs are annually contracted to produce quantities of quality declared seed. Use of these NGOs has enabled the programme to increase the area of land under seed production and to produce seed in all regions of Afghanistan. A total of more than 5,500 tonnes of seed of various crops were produced in 1995 and 1996.

Community In 1995 farmers were asked to form groups within their communities to produce and distribute seed. Under this scheme in which, due to the direct involvement of the community, there is an element of sustainability and a more equitable distribution of seed, communities were provided with foundation seed and DAP free of cost but incurred the costs of production and distribution themselves. Proceeds from the sale of seeds are used for further strengthening of seed production activities: in 1996 more than 300 tonnes of seed were produced and US\$14,565 generated through the seed sales.

\section{Production of quality declared seed and its distribution with fertilizer}

In the absence of any official government body the responsibility for testing varieties, preservation of germplasm; multiplication of breeder and foundation seed and guaranteeing seed quality has become the responsibility of the AFG/94/002 programme. However, it is not possible for a programme such as this to officially guarantee or certify the seed produced by more than 10,000

${ }^{1}$ Seed of the highest level of purity direct from the breeder

${ }^{2}$ High quality seed intermediate in the process of producing improved commercial seed available for sale to farmers from breeder seed

\footnotetext{
${ }^{3}$ Improved variety seed of a "declared" quality standard produced by the programme for sale to farmers
} 


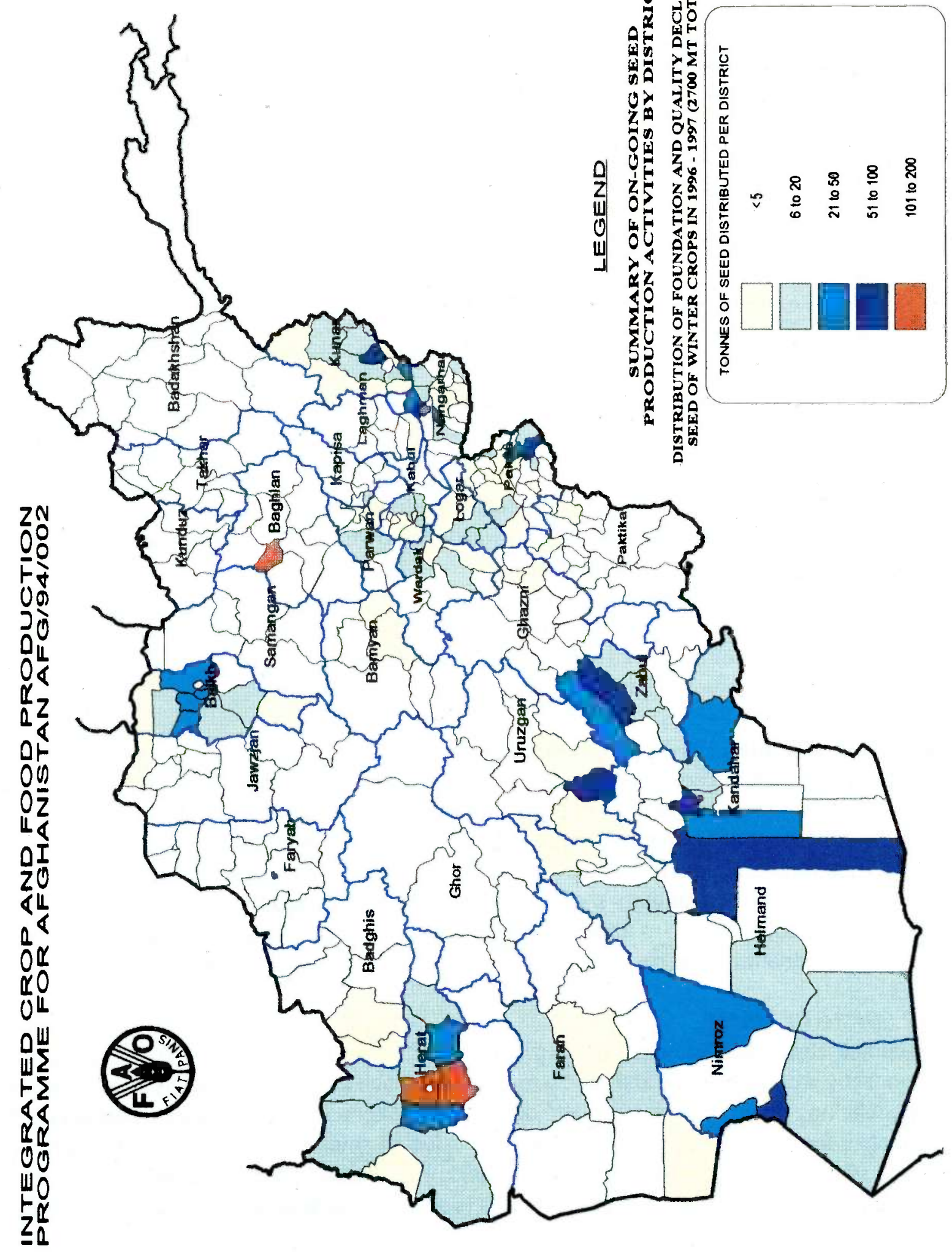


seed growers to be of a certain definitive quality. Consequently, the programme is producing "quality declared" seed which has its own level of authenticity amongst Afghan farmers.

In 1995 and 1996 a total of approximately 17000 tonnes of seed was produced by the various producers of which about 7000 tonnes was procured by the project for redistribution, farmer to farmer exchange taking care of the redistribution of the remaining 10000 tonnes.

Table 1 Seed Production in 1995 and 1996

\begin{tabular}{||c|c|c|}
\hline Crop & 1995 (tonnes) & $\mathbf{1 9 9 6}$ (tonnes) \\
\hline \hline Wheat & 4779 & 6561 \\
\hline Barley & - & 171 \\
\hline Rice & 626 & 1088 \\
\hline Maize & 696 & 1546 \\
\hline Pulses & 124 & 814 \\
\hline Cotton & 154 & 261 \\
\hline \hline & $\mathbf{6 3 8 0}$ & $\mathbf{1 0 4 4 1}$ \\
\hline
\end{tabular}

The success of the programme can be attributed to the following factors:

* Selection and participation of farmers who are known for their integrity and hard work

* Direct involvement of the communities

* An effective partnership with NGOs

* Collaboration between FAO and other UN agencies: UNDP, WFP, UNDCP and UNHCR

* Re-distribution of improved seed in rural areas by farmer-to-farmer exchange

* Additional financial assistance received from various donors.

\section{Opportunities for the 1997-99 programme}

* Establishment of seed growers associations based on community participation

* Emphasis to be on "quality": of personnel participating and of the training offered

* Establishment of clusters of "seed villages" for the production of quality seed

* $\quad$ Agricultural credit facilities to meet the financial needs of seed producers

* $\quad$ Construction of community seed processing and storage facilities

* $\quad$ Establish mobile units to undertake threshing and seed processing on a contract basis

* $\quad$ Seed production to be sustainable by making it a totally commercial enterprise.

\section{CROP IMPROVEMENT}

In wheat and barley leaf and stem borne diseases such as rusts reduce yields by reducing the photosynthetic area of the plant and seed borne diseases such as smuts drastically reduce yields and effect baking quality by attacking and destroying the kernels. In the rainfed wheat areas of Afghanistan, for example, up to $30 \%$ of the crop is lost to smut diseases. The development of resistant varieties in plant breeding programmes is an effective and sustainable way to overcome such problems and in the new varieties of cereals produced resistance to rust and smut diseases are desired characteristics.

The purpose of every crop improvement program is to identify potential varieties by testing in field trials under local conditions lines possessing characteristics that enable them to outperform those varieties currently in use. Whereas some varieties are inherently higher yielding than others performance may not be solely judged by a potential for high yield because under local field 


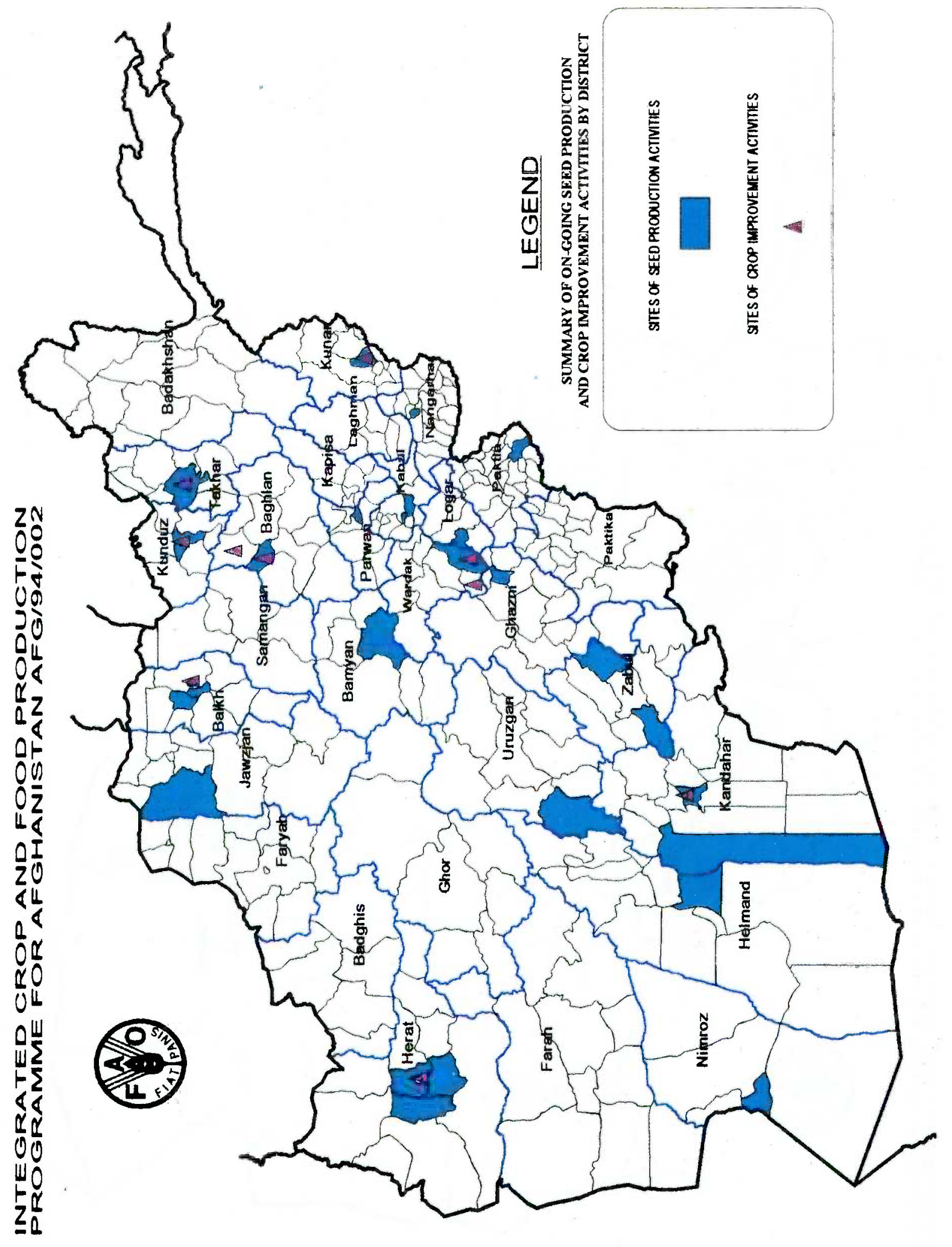




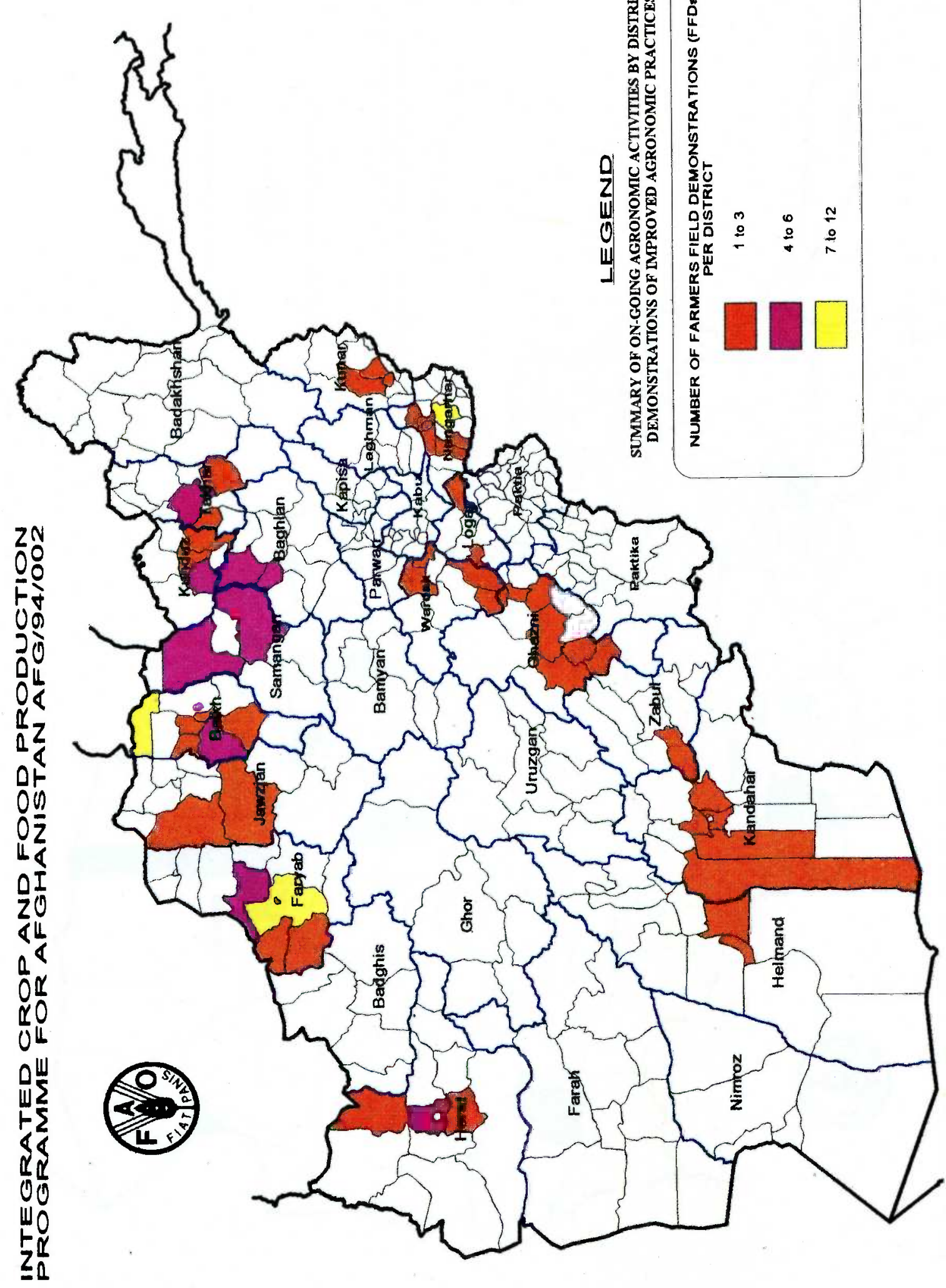


conditions other characteristics may be more important. Preferred characters might be a short growing season or maturation period; resistance to disease or insect pest attack; some varieties might be more tolerant of water stress or be of a different growth habit, short stemmed as opposed to long stemmed, for example, that gives their use some advantage over those presently used by farmers. In general, of course, one is looking for a combination of desired characters that enhance performance under local field conditions and offer a better return for the farmer.

Between 1979 and 1988 most cereal varieties in use became susceptible to new races of endemic diseases and few if any new varieties were tested or introduced. From 1988 to 1995 the Swedish Government, implementing through international NGOs, supported small scale crop variety trials at three locations in Afghanistan to test the performance of new varieties of cereals. In 1996 these activities were integrated into the AFG/94/002 programme again with funding from the Swedish Government, but with implementation based on the six FAO offices. Using field trials the objective of the current crop improvement programme is to test and select varieties of cereals (wheat, barley, rice and maize) for high yield and disease resistance and to produce small quantities of breeder and foundation seed for further multiplication inside Afghanistan by the seed production element of the programme.

In practice this means that, say, 10 grams each may be obtained of 500 new lines of wheat breeder's seed ${ }^{4}$ from the various sources (see text), which after testing, selection and multiplication may produce, say, $500 \mathrm{~kg}$ of pre-basic seed ${ }^{5}$ of the selected line which may be only one of the lines received from the original source. Pre-basic seed is given to the seed production element of the programme where it is multiplied to produce foundation seed. Multiplication of the foundation seed produces the "quality declared" seed which is sold to farmers for grain production. Training in the production of high quality seed is conducted for farmers, contract seed growers and staff of the local departments of agriculture.

\section{Results of testing new varieties of Wheat}

Lines of breeder seed have been obtained from CIMMYT; ICARDA; Pakistan; India and Iran. The average yield of irrigated wheat is presently estimated at 1.75 tonnes/ha. The programme conducted variety performance trials in 1996 harvest season and the ten highest yielding wheat lines (5.03-6.54 tonnes/ha) with a high resistance to rust disease were selected as improved varieties for multiplication and release to farmers. For 1997 harvest season a large number of experimental lines of wheat were received from both international research centres. These lines, plus those from the 1996 season, will be further tested for disease resistance and yield.

The average yield of rainfed wheat is presently estimated at 0.43 tonnes/ha. Two high yielding disease resistant wheat lines with an average yield of 1.7 tonnes/ha are being increased for rainfed agriculture in northern Afghanistan. For 1997 harvest season these two plus a large number of other lines are being tested.

The programme is also responsible for producing recommendations, determined in field trials, of agronomic practices under local conditions for varieties of cereals being introduced to farmers for the first time. A number of experiments on planting date, fertiliser rates and sowing rates have been planted to determine the optimum agronomy, at different locations, for new crop varieties.

\footnotetext{
${ }^{4}$ Seed of the selected line identified as a potential variety very early in the plant breeding process
}

${ }^{5}$ In the plant breeding research phase - seed produced from breeder nucleus seed (a small quantity of a single line selected by the breeder based on the desired characteristic) 
Wheat variety trials Qandahar
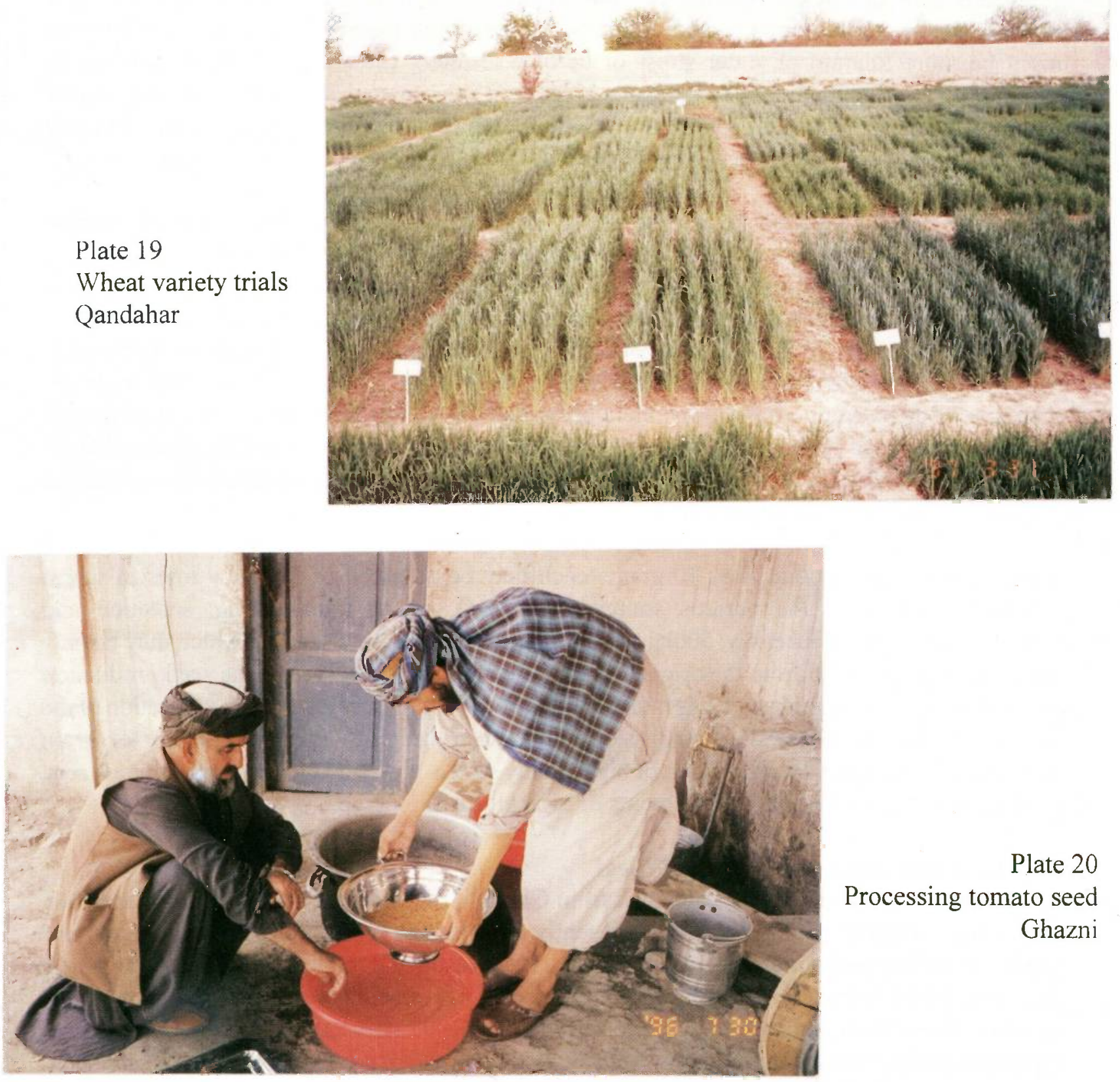

Plate 20

Processing tomato seed

Ghazni

Plate 21

Seed Merchant Balkh

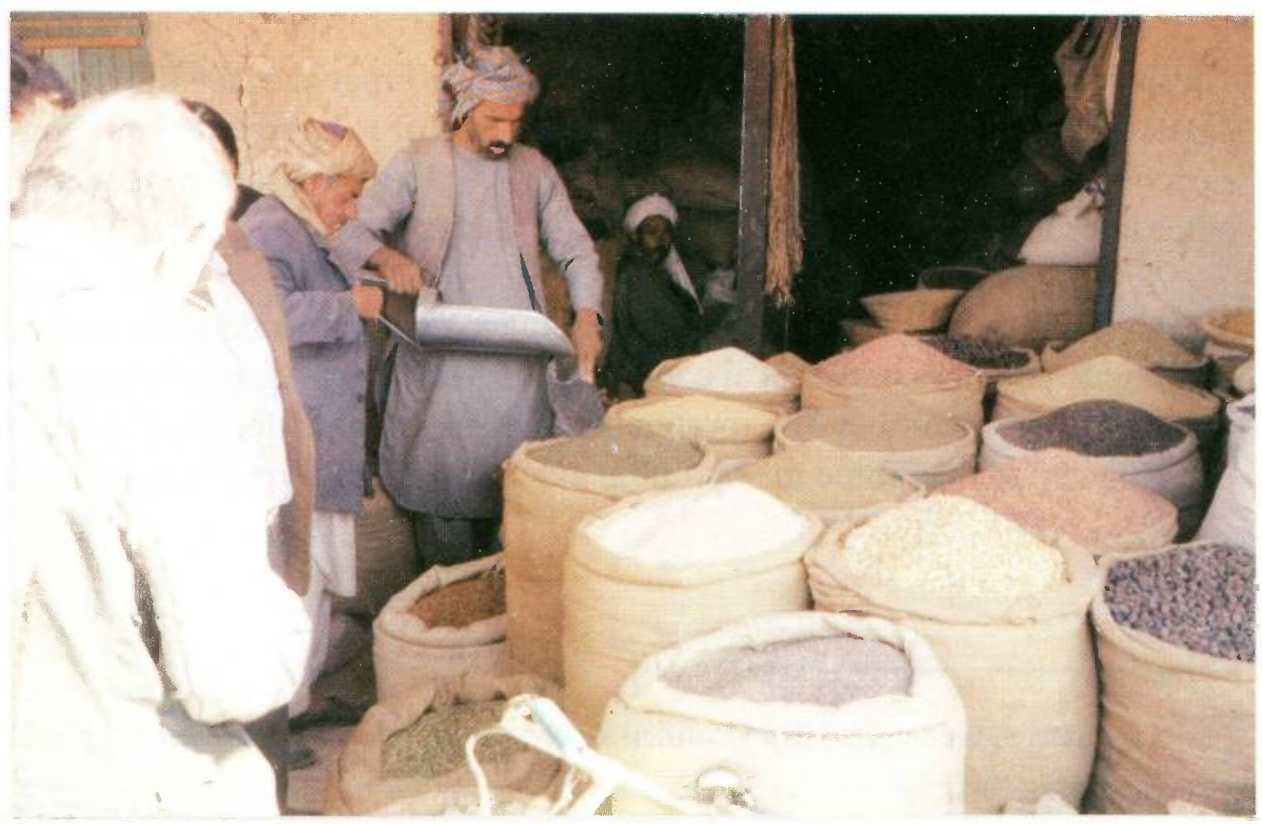




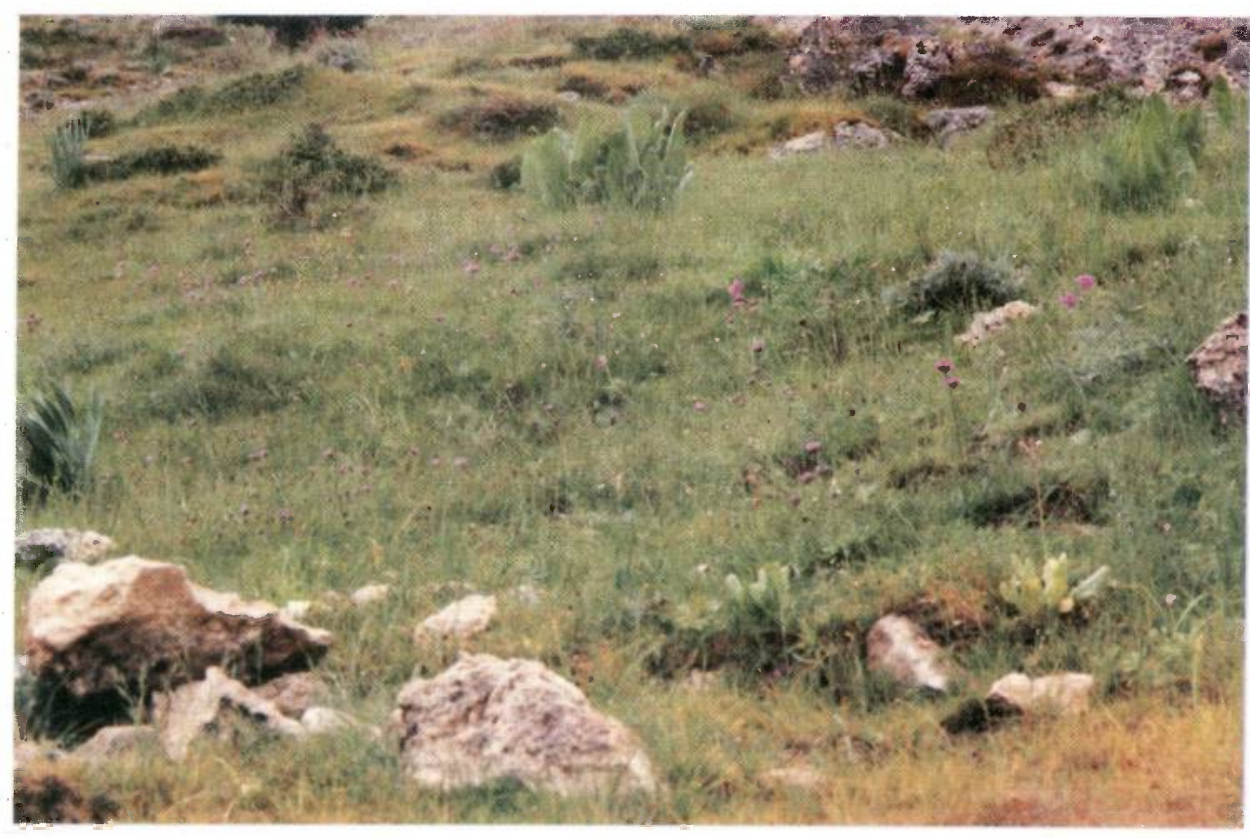

Plate 22

A plant genetic resource:

an alpine meadow

Saripul

Plate 23

Pistacchio

Badghis
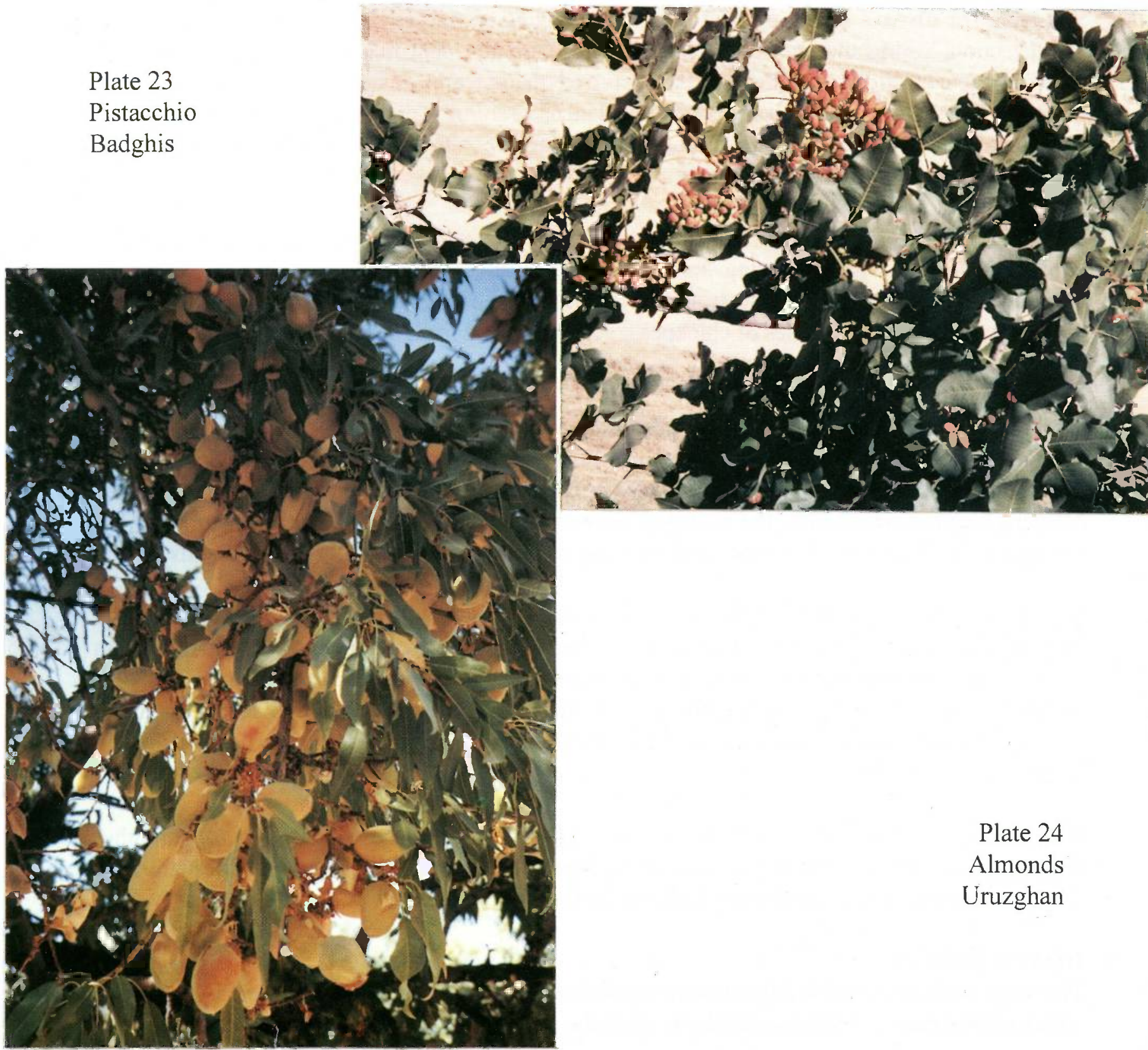

Plate 24

Almonds

Uruzghan 


\section{Results of testing new varieties of Rice}

Lines of breeder seed have been obtained from IRRI. Rice is an important crop in parts of northern and eastern Afghanistan. A number of trials have been carried out and these showed that the short grain varieties Swat-2, JP-5, DR-83 and Pakal are highest yielding. The lines RP16707613-32, IR-50, Ravi-1328 and Arongana 688, plus those selected from northern Afghanistan, will be tested for yield in 1997. A promising long grain variety, Basmati-385, is currently being multiplied in farmers fields. Eight new long grain lines will be tested in 1997.

\section{Results of testing new varieties of Maize}

Lines of breeder seed have been obtained from Pakistan. Maize is an important component of the diet in many parts of Afghanistan. The program has identified that varieties EV-2 and Shaheen produce high yields at high altitude whilst the variety Azam is well adapted to the warmer areas of the country. The varieties Kissan, Sarhad Yellow and Sarhad White are adapted to both cooler and warmer areas of Afghanistan.

\section{Selection for disease resistance amongst local varieties; preserving a genetic resource}

The selection, testing and multiplication of lines of varieties identified as being adapted to local agroclimatic conditions and showing the preferred characters is an economical and sustainable method of obtaining quality planting material. The programme is collecting, testing and selecting from local lines of cereals and leguminous crops varieties showing the preferred characters of resistance to locally important diseases.

Afghanistan is part of the region in which, it is believed, wheat, chickpeas and lentils originally evolved. Rainfed wheat growing areas contain mixtures of ancient varieties of wheat. In collaboration with IPGRI a collection is being proposed of local varieties from Afghan wheat fields, plus other local varieties of chickpeas, vegetables and fruit, to preserve a genetic resource of international importance.

\section{Opportunities for the 1997-99 programme}

The current programme has focussed on cereal crops, the next phase will expand to include leguminous and oil seed crops. Work will also be carried out on the legumes and cereals of mixed cropping regimes which have the potential to improve soil fertility through the activities of the nitrogen fixing bacteria of legumes and increase the variety of foodstuffs in the nations diet.

In co-operation with the horticultural section a varietal purification project has been launched for 1997 in which some 20 local and imported varieties of different vegetables are being purified in each region to produce foundation seed. The production of potato from true potato seed will also be investigated. It is hoped that this strategy will enable the programme to produce and distribute high yielding disease resistant and virus free potato varieties thus adding significantly to food security in the country.

Integration, on a sustainable commercial basis, of the crop improvement component with other sectors, particularly with seed production, could significantly assist Afghan farmers by establishing the foundation of a seed production industry and reduce the demand for imported seed.

\section{HORTICULTURE}

The range of climates inside Afghanistan, together with the hard winters and low relative humidity which reduce pest and disease problems, give the country's horticultural sector (fruit, nuts and 


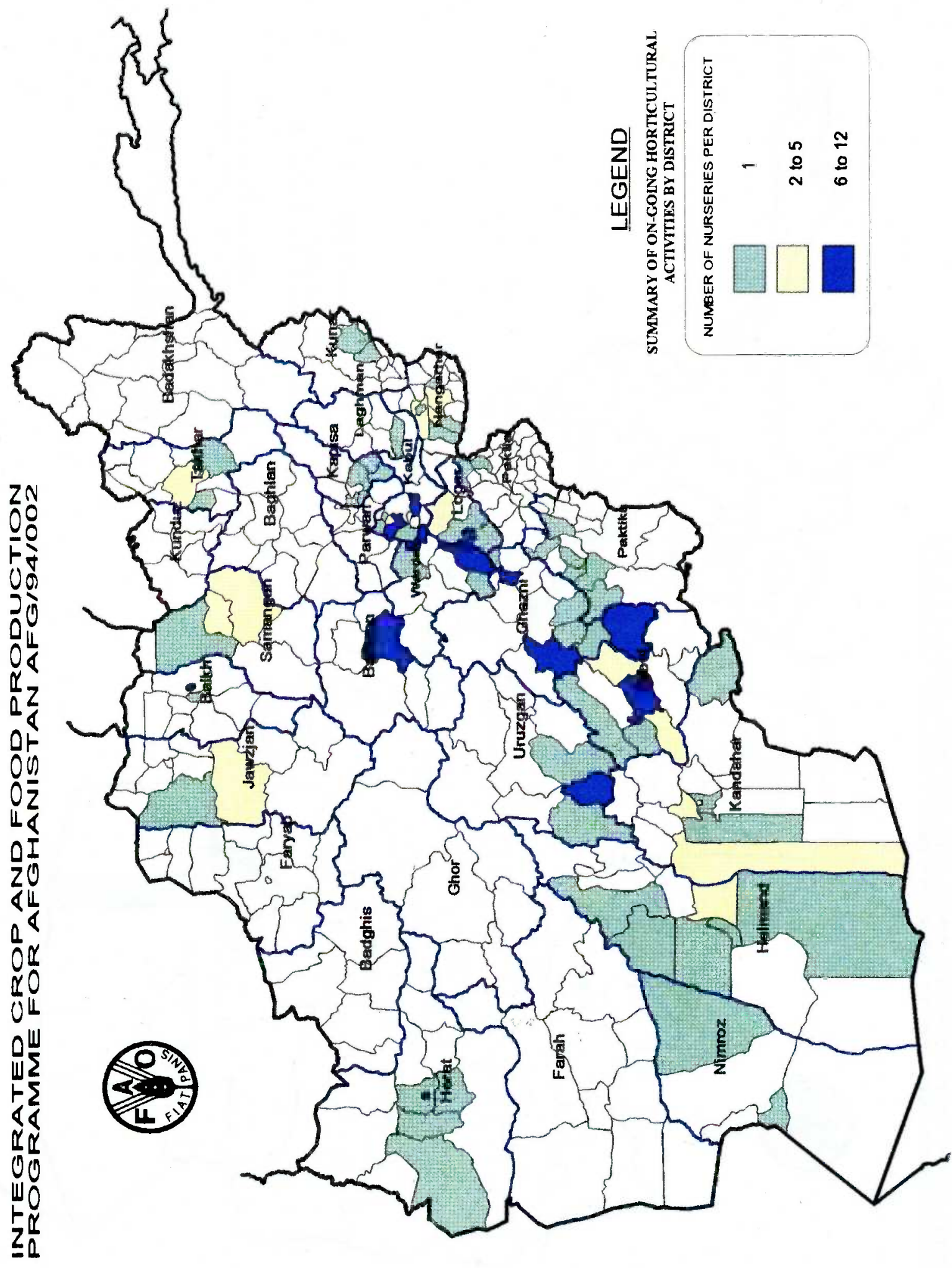




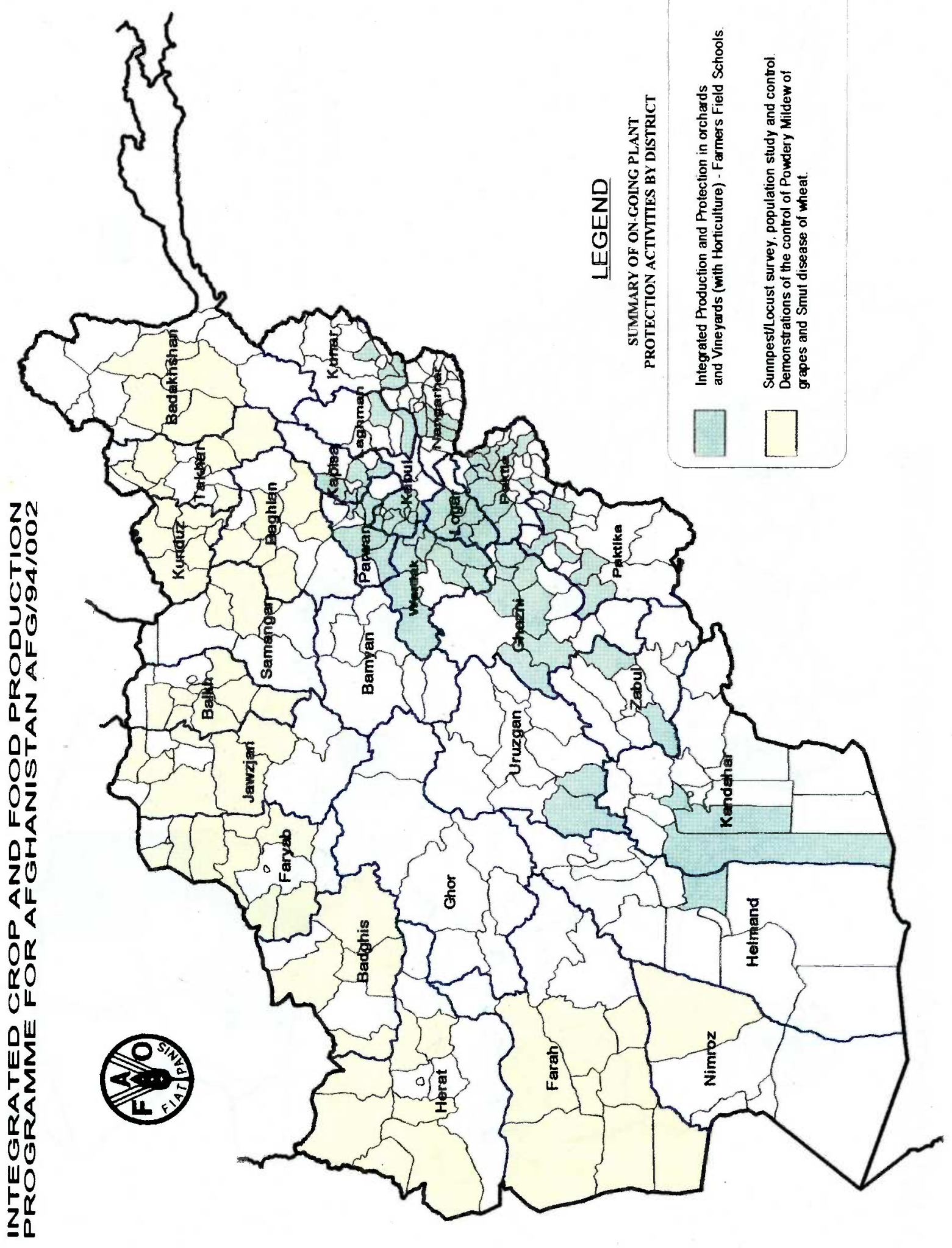


vegetables) enormous potential for development. Afghanistan grows a rich variety of crops: citrus, olive, apple, pear, apricot, peach, plum, cherry, almond, walnut, pome mulberry and grape. Historically, the export of dried fruits was the major source of hard c for the Afghan exchequer: prior to 1979 fruit production accounted for $37 \%$ of Afghan stan's foreign exchange earnings, $70 \%$ of these earnings were from the export of raisins.

In the past, FAO has managed a number of horticultural programmes funded by UNDP and UNOCHA and implemented by NGOs as part of the emergency to support returning refugees: FAO initiated a programme in 1989 to supply 1.5 million budded fruit trees to returnees for the re-planting and re-establishment of village orchards. This was followed in 1990 by support through the provision of agricultural inputs and planting material to establish a network of nurseries to re-establish the nation's capability to meet its demand for orchard and amenity trees. The programme supporting sixty-nine NGO managed nurseries was withdrawn in 1995 enabling their plant production activities to continue on a commercial basis.

In the vegetable sector, before the war, several provinces of Afghanistan were famous for supplying summer and winter vegetables to local and export markets. Following the disruption caused by the war, communities and families were mostly concerned with food security and their needs to rehabilitate crop production for both subsistence and income generation. In 1989, FAO initiated a vegetable production programme by distributing large quantities of imported vegetable seeds to returning refugees. Vegetable crops being of high market value have the potential to generate an important cash income to small landholders within the period of a short crop cycle. In this way vegetable crops can play a significant role in facilitating the sustainable resettlement of returnees and assist reform: in crop substitution programmes concerning poppy cultivation.

\section{Fruit crops - Nurseries}

The long term strategy of the horticulture programme is to develop on a commercial and sustainable basis Afghanistan's national capacity to cater for its own needs. The programme supports the local production of high quality fruit and amenity trees through the establishment of strategically positioned, commercially oriented, and self-sustaining nurseries. In implementing this strategy, since the start of 1996, progressive farmers have received direct support to establish their own private, commercial nurseries under a joint FAO/WFP programme.

In 1996, 66 new private fruit tree nurseries were established in a total of 19 provinces and, encouraged by the success, a further 97 nurseries will be established by the programme in 1997 . Each nursery has the potential to produce a minimum of 10,000 saplings per year, and the opportunity to become a sustainable commercial enterprise following a maximum period of assistance of two years.

By the end of 1998 , through this nursery programme, there will be an estimated annual national capacity to produce $1,500,000$ budded fruit tree saplings: sufficient to replant or rehabilitate 3,000 hectares of orchards each year and equivalent, once the orchards produce $30 \mathrm{~kg}$ of fruit per tree, to an annual increase of 45,000 tonnes of fruit. Should all the nurseries be successful, produce the targeted output for ten years and provided all the output is used in-country, Afghanistan will have rehabilitated sufficient orchard capacity to realise half of the pre-war (1976) national production of about 900,000 tonnes of orchard fruits.

Before the war Afghanistan was known to have a wide range of indigenous fruit species, particularly of stone fruits and nuts. Unfortunately, many local species and cultivars have since been destroyed: a tremendous loss of a plant genetic resource of international significance. In order to rehabilitate and preserve the remains of this resource a network of "nucleus" nurseries has been established where collections of local cultivars are maintained and where private nursery 
Plate 25

Grapes on earth

Herat
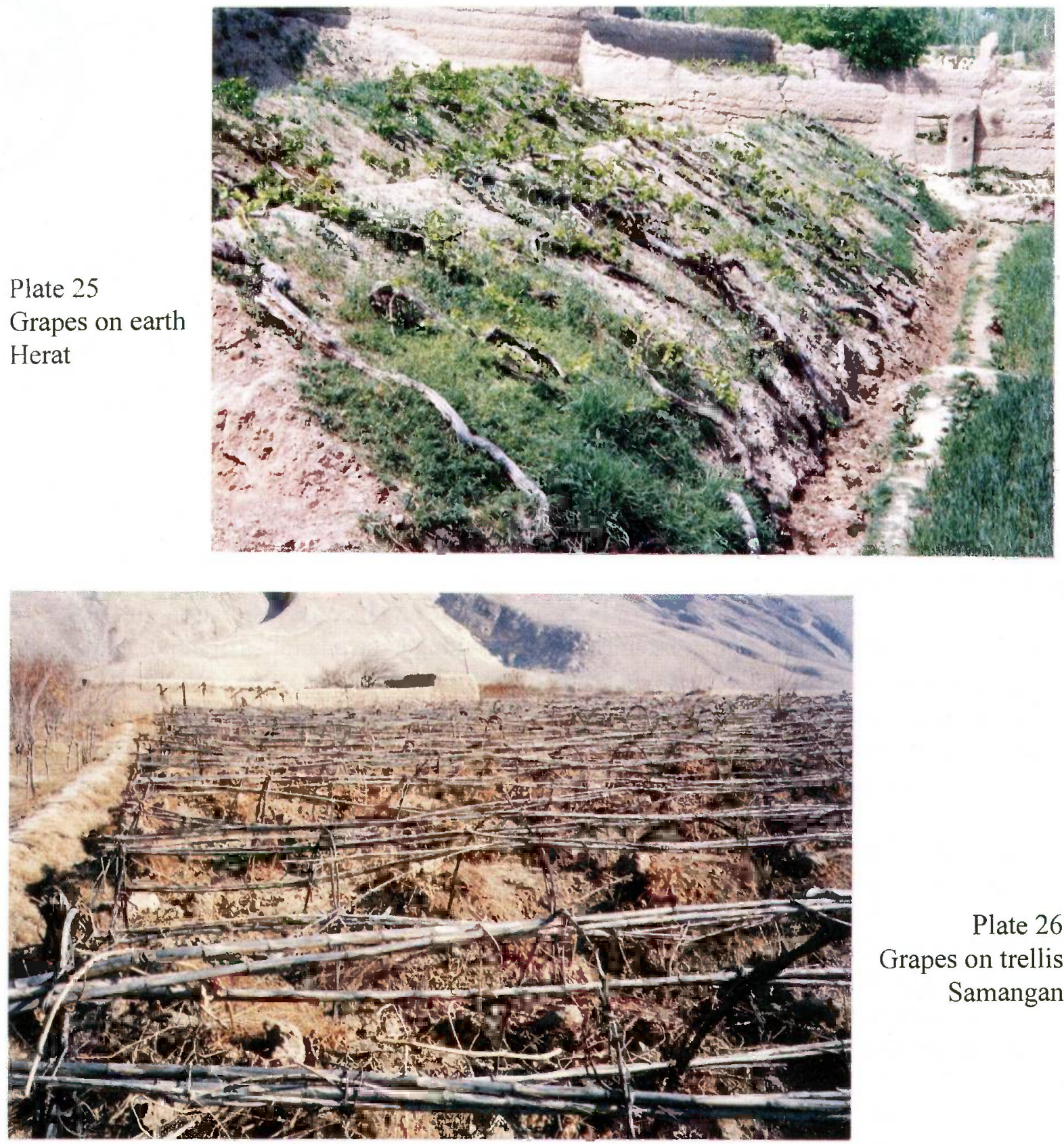

Plate 26

Grapes on trellis

Samangan

Plate 27

Grape varieties

Qandahar

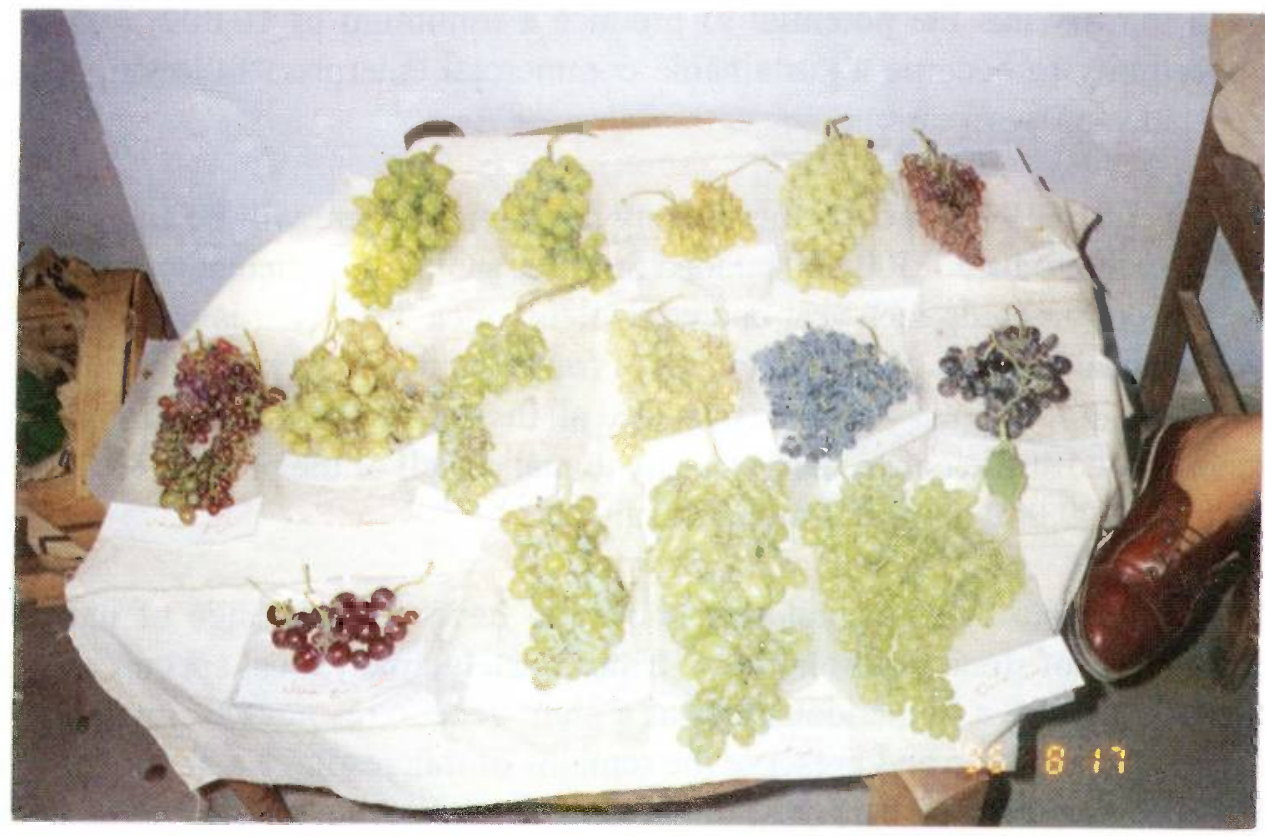


growers can utilise a national resource and have the benefit of quality controlled foundation planting material. These "nucleus" nurseries are also used as training centres for nursery growers.

\section{Fruit crops - Orchards}

The programme is concerned with optimizing the impact of the rehabilitation of orchards based on the production of quality planting material produced by private nurseries. In 1997, plant protection and horticulture elements together launched an extension programme based on farmers field schools for fruit farmers in eastern and southern Afghanistan (see Introduction).

The major constraint on the future development of the Afghan fruit industry is poor orchard management. An FAO consultant pomologist was recruited in late 1996 to assess Afghan orchards and to make recommendations for a solution to the problem. In early 1997 a workshop was convened in Peshawar to which all NGOs involved with the implementation of horticultural programmes were invited. At the workshop a unified technical message was prepared concerning orchard management practices that will be the basis for future extension material and training courses for all Afghan fruit farmers.

Following the workshop the consultant held training courses in Jalalabad; Logar; Ghazni and Qandahar for NPPPs and about 100 district trainers involved in the implementation of the integrated production and protection extension programme, plus field staff from other NGOs; staff from departments of agriculture and some local farmers. The programme now has a unified technical message, an extension service based on FFS and a number of trained extensionists beginning to train farmers.

\section{Dried Fruits}

Farmers are being trained to produce dried apricots cured with sulphur. The product is of high quality and high value, but marketing is a problem since the quantity produced is still very small. As a response to the high return many almond farmers are replanting their orchards with apricots.

\section{Vegetables}

The objective of the programme is to develop vegetable production on a sustainable basis making farming communities self-reliant in high quality vegetable seed. In 1996, a programme was initiated to train farmers in methods of improved crop management and purification of local vegetable varieties enabling them to produce foundation seed for redistribution to community vegetable seed growers.

Kitchen gardens have the potential to address the problem of malnutrition in families and to promote the role of women in community development. Despite the political and social constraints on the participation of women in production and development activities outside the family compound 120 women have been trained in improved methods of vegetable production as part of kitchen garden programmes.

\section{Planning the development of horticulture}

In general, production should be market oriented. Currently, there is very little marketing of Afghan horticultural produce by farmers, either in groups or alone, for example, apples are sold whilst still on the trees to itinerant wholesalers. The average farmer does not visit markets or have any information on the opportunities to market his produce. Opportunities should be identified and a strategy developed for the marketing of Afghan horticultural produce.

Horticultural support programmes since the start of the war have been based on an "ad hoc" approach to answer immediate needs and not on any planned developmental strateg: no data having been collected in the intervening period to assess the status of the horticultural sector. 


\section{Plate 28}

Locust swarm

Samanagan.
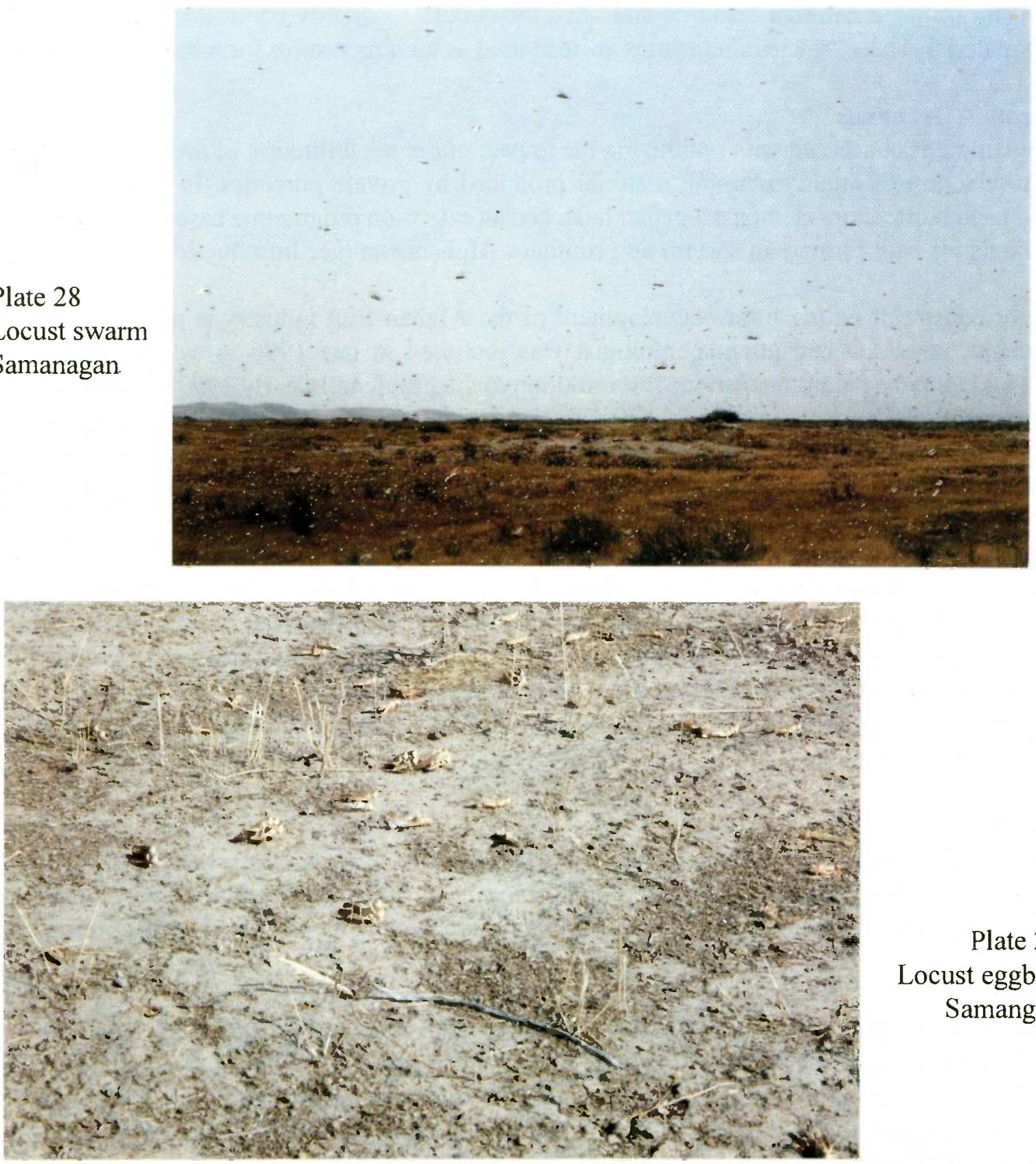

Plate 29

Locust eggbed

Samangan

Plate 30

Locust damage to wheat Balkh

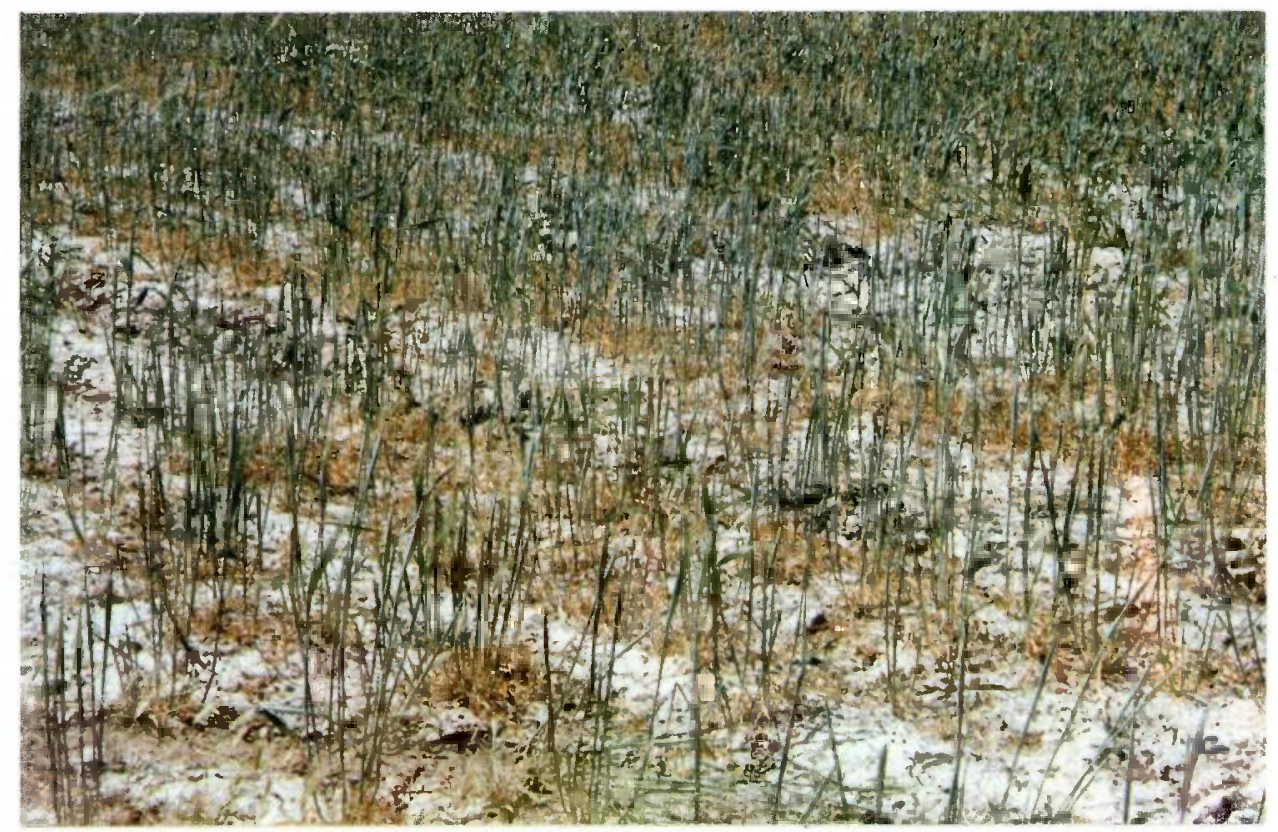




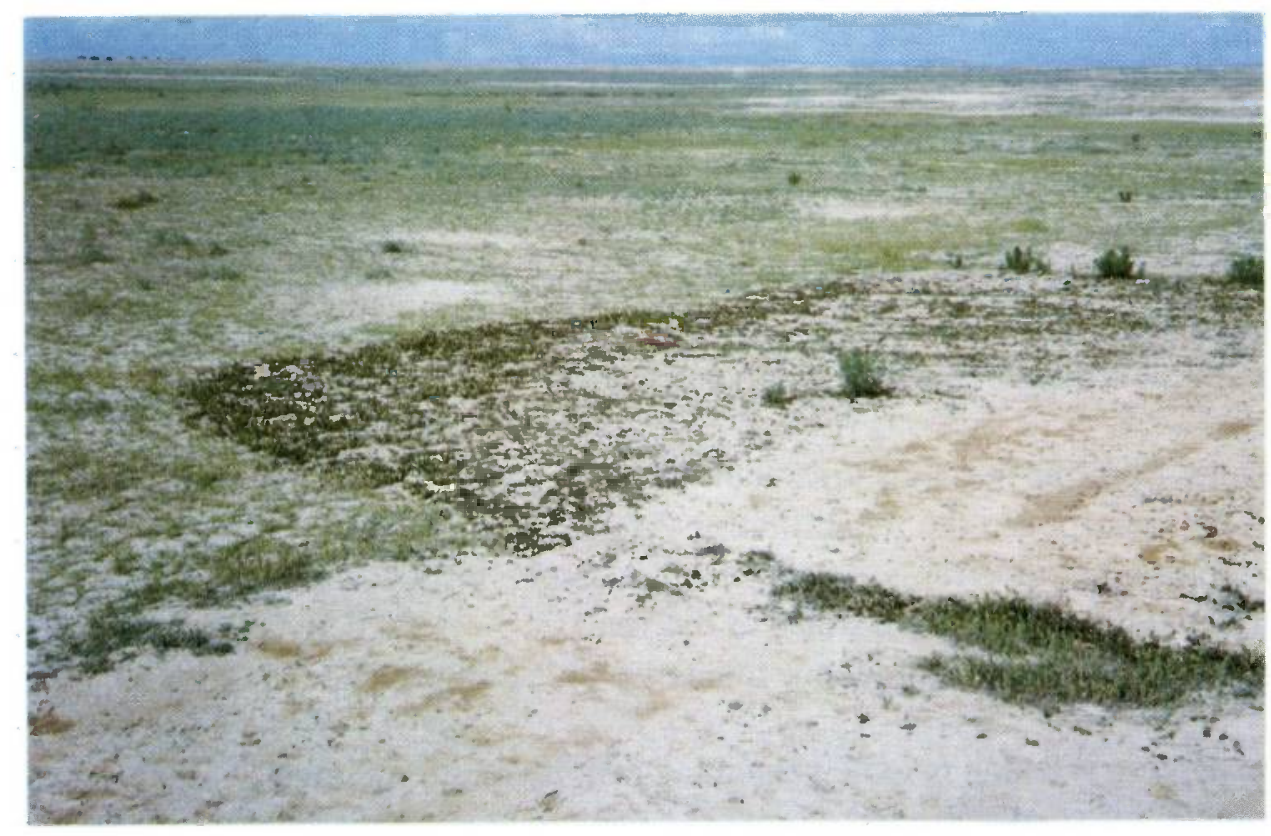

Plate 31

Locust hopper band

Balkh

Plate 32

Locust: mechanical control Balkh
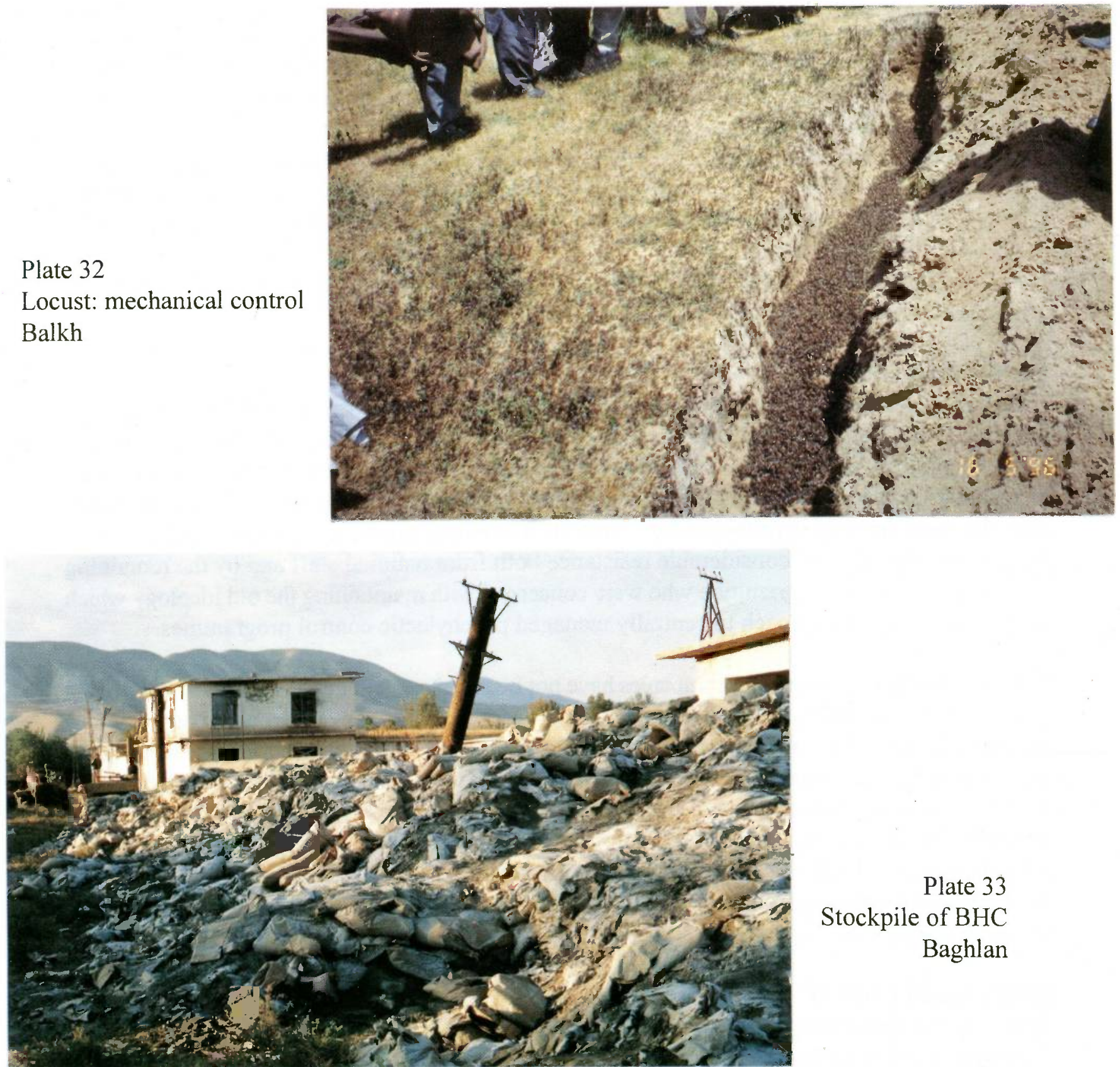

Plate 33

Stockpile of BHC

Baghlan 
Now that most of Afghanistan is peaceful and the majority of small landowners have returned to their villages there is a need for a long term plan for the development of Afghan horticulture. Such a plan would adopt the strategy of sustainable agricultural development responsive to each community's needs, empowering farmers to identify and solve their own problems.

An exhaustive village level survey has begun collecting data in 79 districts selected for their farming-system, all provinces being represented. A baseline study will follow to identify rehabilitation needs and appropriate strategies for long term sustainable horticultural development.

An initial assessment of results from the survey shows that the horticulture sector is in a very strong position to support food security and the rehabilitation Afghan agriculture:

* Horticultural crops represent a wide range of species that can be grown in a variety of agro-ecological zones and thus at different times of the year

* Horticultural crop production is land and labour intensive: an advantage for small land owners

* Horticultural crop cultivation is a high income generating activity requiring limited initial investment: an advantage for small farmers

* Horticultural crops are relatively "water-efficient" (high income generation per unit irrigation water consumed): an advantage in Afghanistan where water is a limited resource

* Most horticultural crops are cultivated using traditional irrigation systems: wells, springs and karez that can be rehabilitated with local resources and limited external support

* Horticultural crops are attractive crop substitutes for the opium poppy

* Horticultural crops include short production cycles (vegetables) and perennial production cycles (fruit and nuts) facilitating sustainable resettlement and agricultural development.

* Peri-urban horticultural development contributes to the alleviation of poverty and malnutrition in urban populations

* Cottage -industry processing of horticultural products generates income for women and additional income for families.

\section{PLANT PROTECTION}

The plant protection programme has adopted strategies which incorporate the general tenets of Integrated Pest Management: empower farmers to make their own decisions, identify and solve their own problems; information and technology transfer by Farmers Field Schools; minimum use of pesticides; conservation of natural enemies; do minimum damage to the environment; tackle only the most important problems and have an immediate impact on farmers incomes. This programme initially met considerable resistance both from national staff and by the remaining provincial ministries of agriculture who were concerned with maintaining the old ideology which adopted a top-down approach to centrally managed prophylactic control programmes.

The multinational agrochemical companies have not been represented inside Afghanistan for many years. A major role previously played by central government was the import and distribution of agricultural inputs. This old dependence on public institutions to act as traders and the subsequent lack of government has resulted in a vacuum which private traders have proved reluctant to fill. In the intervening period farmers have had very limited access to agrochemicals and those pesticides available in the bazaars are mainly old and expired broad spectrum products. This has proved beneficial to the FAO programme which between 1995-97 has been concentrating on developing and introducing novel methods of pest and disease control utilising minimum use of inputs, probably best illustrated in the control of Moroccan Locust (see below).

\section{Plague Insect Control}

There are two important plague insects in Afghanistan, both capable of causing major losses to the wheat crops in the northern provinces: Moroccan Locusts (Dociostaurus moroccanus) and 
Sunn Pest (Heteroptera: Pentatomoidea), plant bugs from several different genera. Prior to 1995 emergency programmes had treated the Moroccan Locust (a fairly predictable univoltine insect which spends nine months of the year as eggs in the ground) as if it were the Desert Locust (a relatively unpredictable, multivoltine insect with a voracious appetite) and had imported large consignments of expensive ULV application equipment and agrochemicals. As a result of these emergency programmes there now exists a stock of ULV agrochemicals and equipment which are not needed for routine Moroccan locust control, but which may be useful in the event of future emergencies. In hindsight. however, it is clear that these control measures, the use of which may be justified in an emergency in a country suffering a civil war, are completely unsustainable at community level.

The policy of community involvement and sustainable development involves the adoption of novel control methods and where possible disregards the use of agrochemicals in favour of well timed mechanical interventions and/or measures requiring minimum inputs incorporated into the farming calendar. In the northern provinces, since late 1995, the plant protection programme implementing through what remains of the PPQD of the provincial ministries of agriculture has been successfully training farming communities to control Moroccan locust by marking eggbeds, monitoring their development and then subsequently destroying the freshly hatched nymphs by mechanical means rather than apply ULV insecticides to control hopper bands. In 1995 2,200 litres of insecticide were used in the locust control programme, in 1996 no chemicals were used, but mechanical control was implemented and control of the locusts still maintained.

Species of Sunn Pest occur from four different genera, but only two of these are considered dangerous: Eurygaster $s p$ and Aelia sp. Monitoring the populations of these insects has identified two species of entomophagous fungi with potential for use in a novel control method using minimum inputs and sustainable at community level (see Programme Proposals).

\section{Integrated Pest Management}

The implementation of IPM in orchard crops was started in 1995. The development of the extension system based on farmers field schools (FFS), first introduced in 1996, is continuing. There are only a very few serious pest and disease problems in Afghan orchards. The lack of access to insecticides and the use of lucerne as an intercrop has ensured that there is a diverse population of beneficial insects in orchards. Farmers are being trained to use agrochemicals as the method of last resort: the misuse and overuse of persistent O-P insecticides such as Metasystox (Oxydemeton-Methyl) has induced high populations of scales, aphids and mites in some orchards.

The IPM programme is being implemented in the orchard crops of eastern and southern Afghanistan. Only the major pest and disease constraints in each crop are targeted and controlled with technology that is readily available in the region. The method used will change as the desired inputs become available, thus, the current method used may not be the least environmentally damaging, but it can be made available to most farmers. Consequently, codling moth is currently controlled mechanically and by timed sprays of the O-P insecticide Lorsban (Chlorpyriphos), whereas when traders are able to import inputs reliably the use of pheromones as mating disruptants or as monitoring agents combined with the less environmentally damaging microbial insecticide Bacterium thuringiensis could become the preferred method.

Mechanical control is used against tent caterpillars which have the potential to defoliate trees quickly. In 1997, with the co-operation of IIBC, Rawalpindi, a parasitic wasp, Aphelinus mali, is being introduced to selected orchards for the biological control of woolly apple aphid. Training farmers in the identification of beneficial insects is an on-going exercise fundamental to the success of the IPM programme. NPPPs have undergone training in biological contro' 'nd in the use of local plants to create "botanical insecticides". 
Plate 34

Weeds in irrigated wheal Balkh
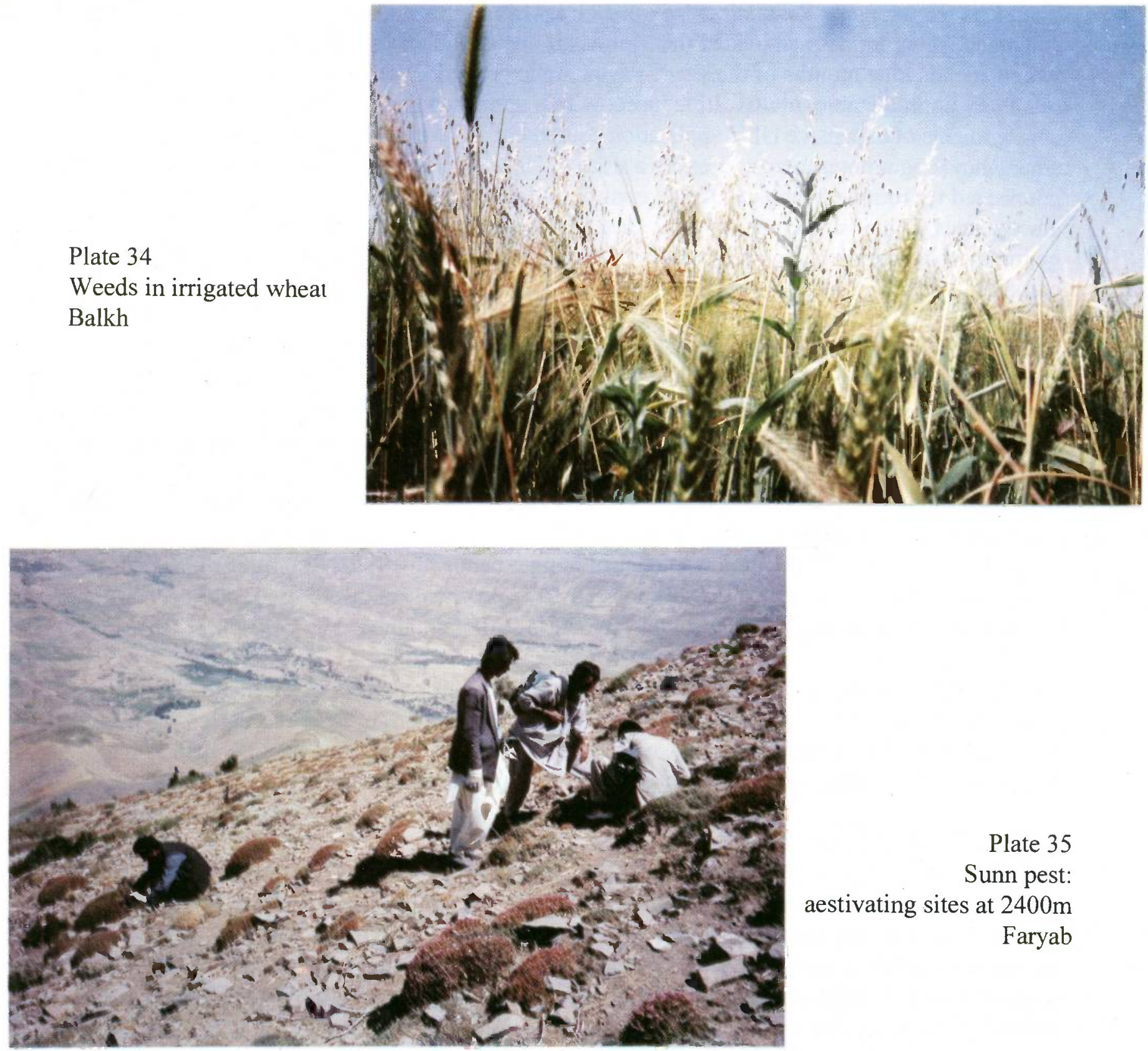

Plate 35

Sunn pest:

aestivating sites at $2400 \mathrm{~m}$

Faryab

Plate 36

Dead sunn pest and entomophagous fungus Saripul

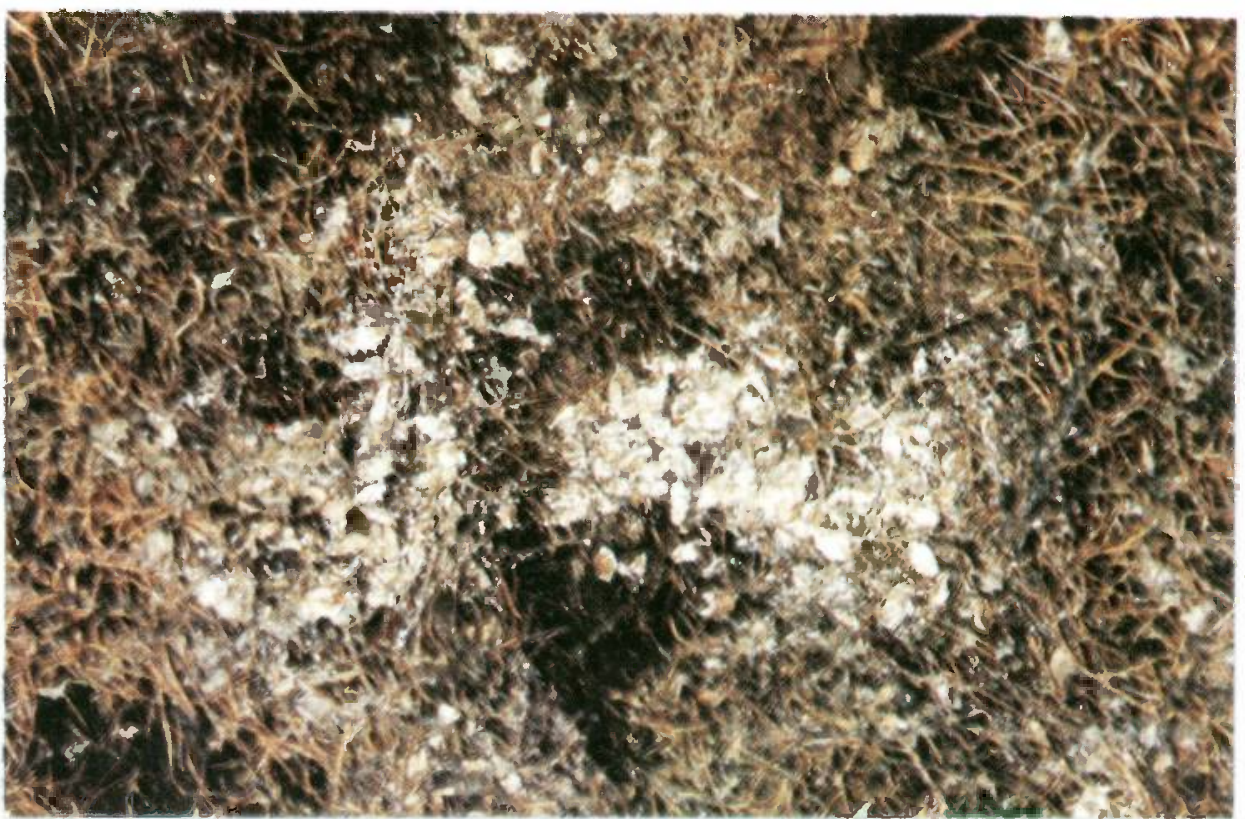




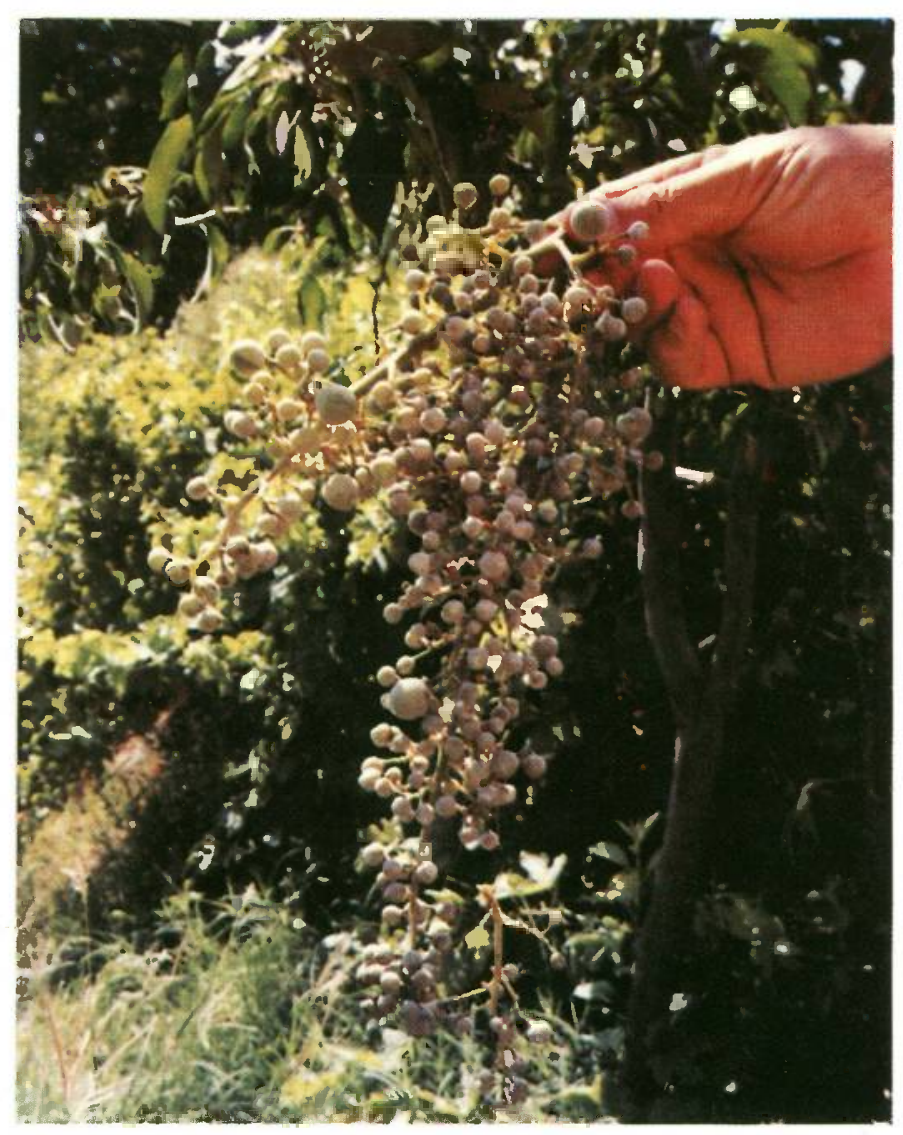

Plate 38

A consultant, the consulted and a large open space Jowzjan

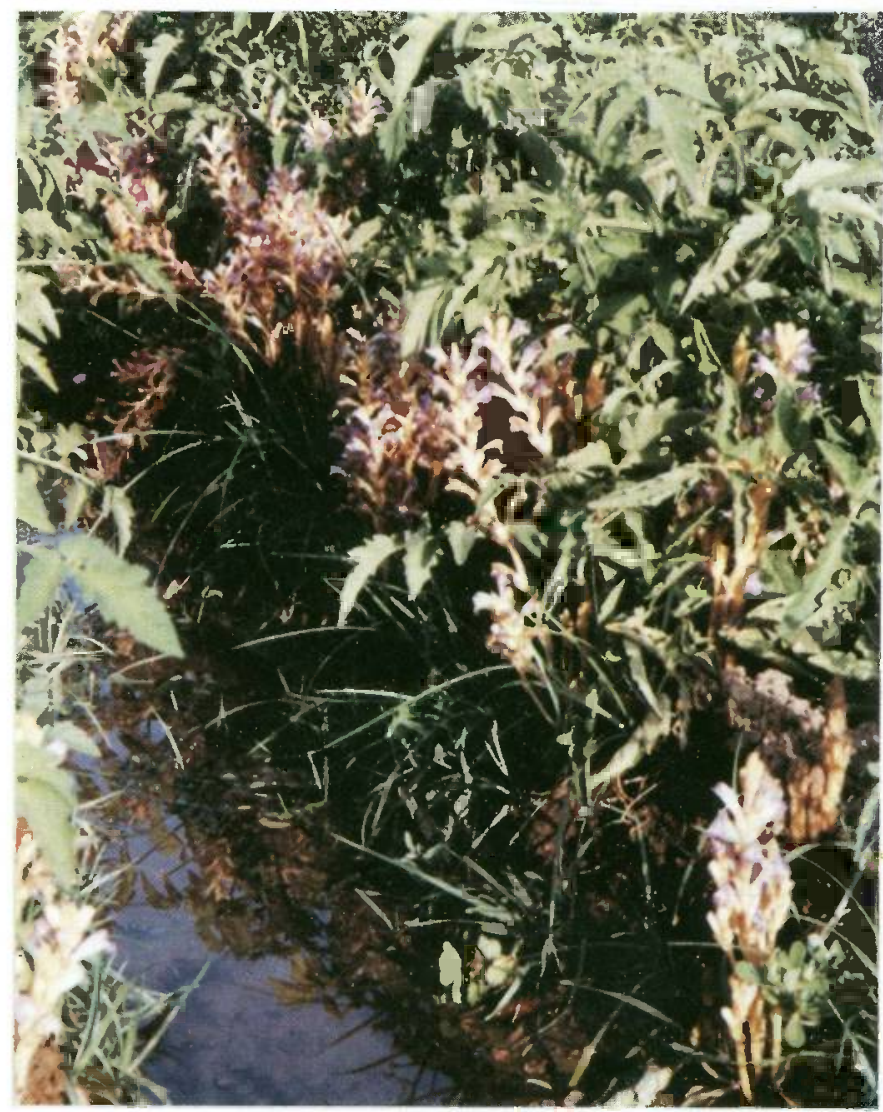

Plate 37

Powdery mildew of grapes

Herat

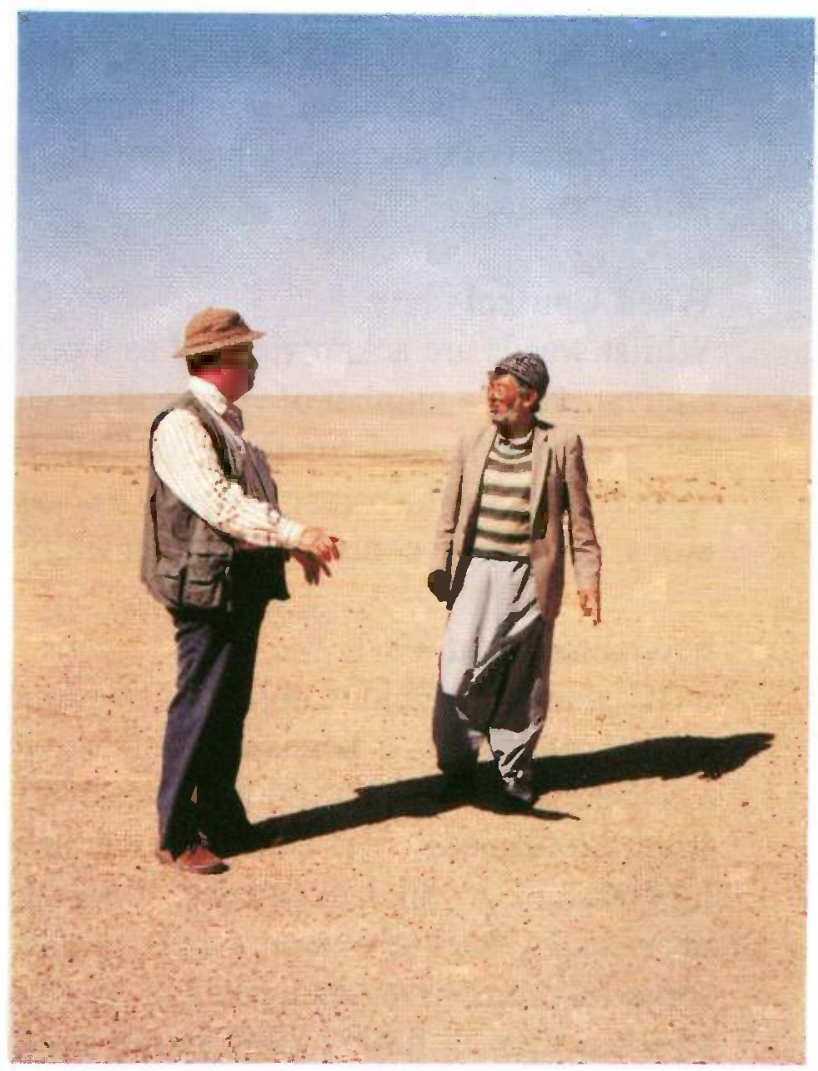

Plate 39

Broomrape, Orabanche $s p$, a parasitic weed on tomatoes

Herat 


\section{Powdery Mildew of Grapes and Smut Disease of Wheat}

These two diseases are responsible for major crop losses and reductions in farmer's income. However, both diseases can be easily controlled by farmers provided the recommended inputs are available for purchase in the bazaars. Powdery mildew of grapes which in most areas, without treatment, causes $100 \%$ crop failure can be controlled very cheaply with a programme using Sulphur. Smut disease of wheat which accounts for up to $30 \%$ crop loss in most rainfed areas can be controlled by a chemical seed treatment. Throughout the northern provinces demonstrations of the control of these diseases have been established.

\section{Melon fly}

For dryland farmers melons are an important crop and source of water. Species of melon fly (Diptera: Tephritidae) are important pests capable of causing total crop loss. The programme has shown that these flies can be controlled by an insecticidal bait ingeniously designed to attract female flies which crave a rich proteinaceous diet in order to produce viable eggs. Further development of these baits which are effective without producing fruits high in pesticide residues will continue.

\section{Weed Control}

Whilst weeds are acknowledged as a problem particularly on land which has remained out of cultivation for a number of years and on land being cultivated for the first time herbicides are not being recommended for their control. Traditional hand weeding is preferred to the use of agrochemicals. The parasitic weed Orabanche $s p$ is a serious pest of solanaceous and cucurbitous crops, but can be controlled mechanically.

\section{Environmental work}

$\mathrm{BHC}$ is an insecticide subject to a voluntary banning procedure from agricultural use. It is a known carcinogen, is persistent in the environment and belongs to the same group of insecticides as DDT. There are some 6000 tonnes of BHC dust stockpiled in the northern provinces imported from the former Soviet Union for use in centrally managed annual prophylactic locust control programmes in which huge areas of desert were routinely dusted. These stockpiles are in rotting paper sacks, stacked outdoors and exposed to all-weathers. In 1996, an AFG/94/002-WFP foodfor-work programme rebagged and removed 1200 tonnes from the environs of Kunduz city into a locked store. A further 2000 tonnes is similarly being removed from the city of Baghlan where it was stockpiled adjacent to the major bazaar. The permanent safe storage of BHC cannot be guaranteed since it is perceived as a free resource by both farmers and commanders.

\section{Opportunities for the 1997-99 programme}

The development of the programme has been by a step by step approach based on removing problems of implementation determined by effective monitoring. Issues such as sustainability, integration of protection with production, penetration of the programme to reach poor farming communities, supply of agricultural inputs by trained agricultural traders, methods of implementation and impact assessment are being continuously addressed.

Since the FFS system is very adaptable additional extension messages can be easily added to the programme. The FFS system is being developed for orchard crops in the south and it can later be introduced to the north with the establishment of new orchards there. IPP in vegetable crops with the establishment of FFS is being planned. The sustainability and scope of the community based mechanical control programme against Moroccan locust will be developed further.

A number of pest and disease problems have yet to be investigated. The re-establishment of cotton as an important crop in the northern provinces may eventually require novel plant protection measures, probably against army worms which in 1996 were reported from several provinces. 


\section{APICULTURE}

Beekeeping with the eastern honey bee Apis cerana has been known in Afghanistan for centuries and this species was still common in the eastern provinces: Kunar (Nuristan); Nangahar and Paktya in 1991. In the mid-1950s an attempt was made to produce honey with this bee on a commercial scale in Kabul, without success. In the early 1960s the government decided to introduce the western honey bee Apis mellifera to Kabul with excellent results, colonies producing ten times the amount of honey as that of the eastern hive bee. As a result colonies of Apis mellifera continued to be introduced and distributed throughout the eastern provinces and to Qandahar in the south and Mazar-i-Sharif in the north. By 1976 there were estimated to be 45,000 bee colonies throughout the country and migratory beekeeping had developed as a means of harvesting all the honey flows in different parts of the country. However, by 1979 an ectoparasitic mite Tropilaelaps clareae had started to invade hives and over the next few years had destroyed about $90 \%$ of the colonies.

\section{Beekeeping in the present day and opportunities for the 1997-99 programme}

The apiculture centre in Kabul and most of the bee keeping equipment stored there was destroyed during the fighting 1992-94. The regional apiculture centres have also been destroyed and beekeeping is mainly confined to the eastern provinces. The last of the Apis mellifera colonies in Mazar-i-Sharif died out in 1995. In 1996 the FAO consultant Dr Zmarlicki who wrote the 1991 report visited Afghanistan to investigate another bee disease reported from Kabul: American foulbrood. This disease and the parasitic mite are now endemic in Afghanistan. In addition to technical information for disease control the industry requires investment in hardware, training and new expertise to revitalise it. The continuing development and rehabilitation of horticulture offers beekeepers a good livelihood for the future. The opportunity exists for the beekeeping industry, including the marketing of honey from Afghanistan, to be redeveloped and strengthened as part of the general rehabilitation of the horticultural industry. Beekeeping will add value to insect pollinated crops and raise the incomes of farmers, it is particularly suitable for the participation of women and the landless and has excellent potential for development.

Approximate budget requirement for redevelopment 1997-99 US $\$ 2,000,000$

\section{SERICULTURE}

Sericulture has been a traditional industry of Afghanistan for centuries, but due to the absence of a source of good quality silkworm eggs inside Afghanistan the silk industry is presently seriously disadvantaged. Nevertheless, sericulture still plays an important role sustaining an estimated 20,000 families in remote and poverty stricken areas providing employment for the disabled, handicapped and aged in silkworm culture, silk production and carpet making.

With limited resources the AFG/94/002 programme has been involved in supporting the revival, expansion and modernisation of the industry: more than 1,000 boxes of silkworm eggs received as donations were distributed in western Afghanistan in 1995 and a consultant was fielded to investigate the establishment of local production facilities for the hybrid silkworm. Absence of specific funding has been a major constraint for the revival of this traditional Afghan industry.

\section{Opportunities for the 1997-99 programme}

* Establishment of commercial production centers capable of maintaining pure silkworm races and with an annual output capacity of 20,000-30,000 boxes of F-1 hybrid eggs.

* Import of at least 20,000 boxes of hybrid silkworm boxes each year for two years (1997 and 1998) until the Afghan facility has been built and producing the required quality and output.

* Production and plantation of improved strains of Mulberry plants.

Approximate budget requirement for redevelopment 1997-99 US $\$ 3,000,000$ 

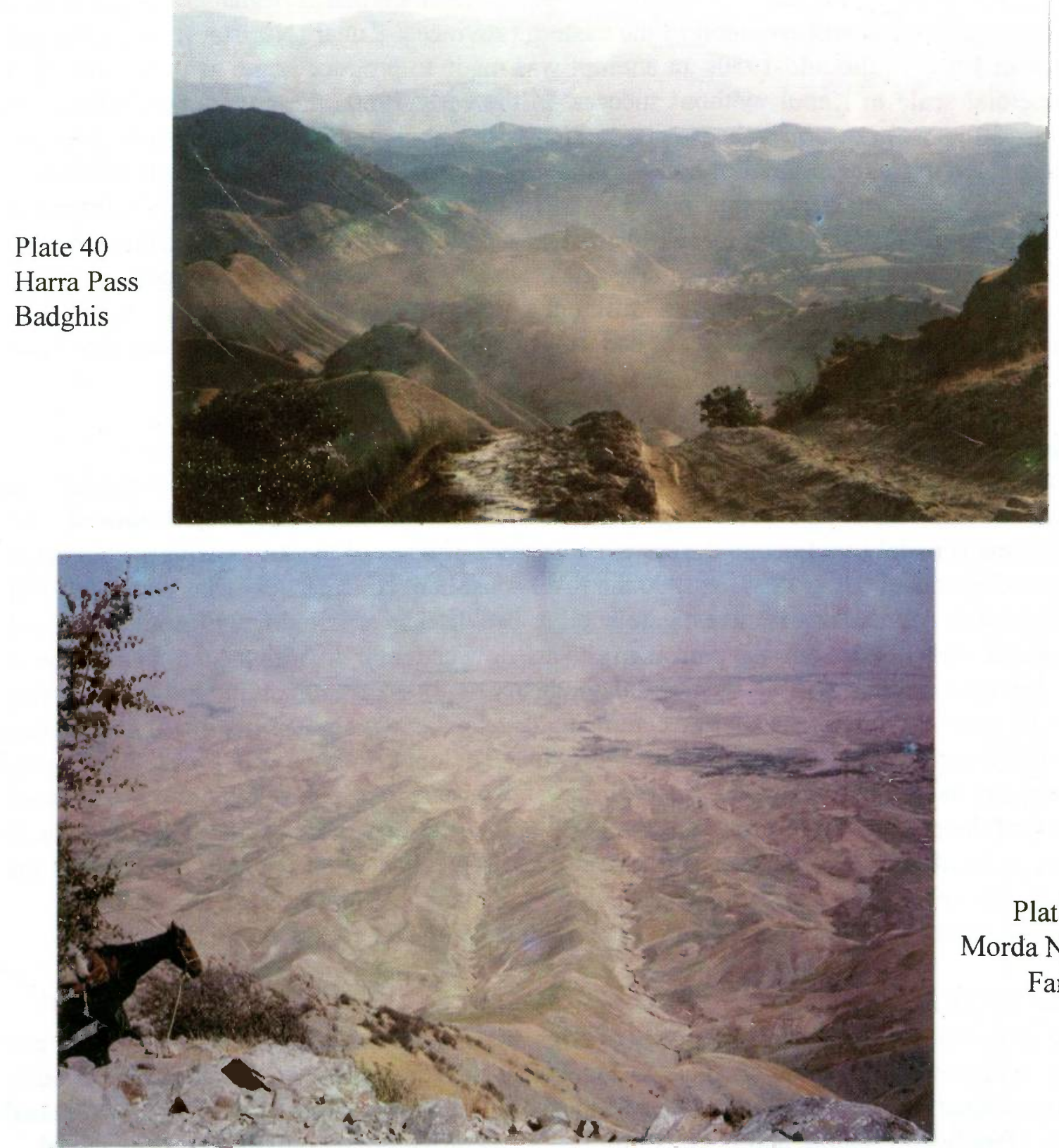

Plate 41

Morda Nyab

Faryab

Plate 42

Langar

Badghis

The End

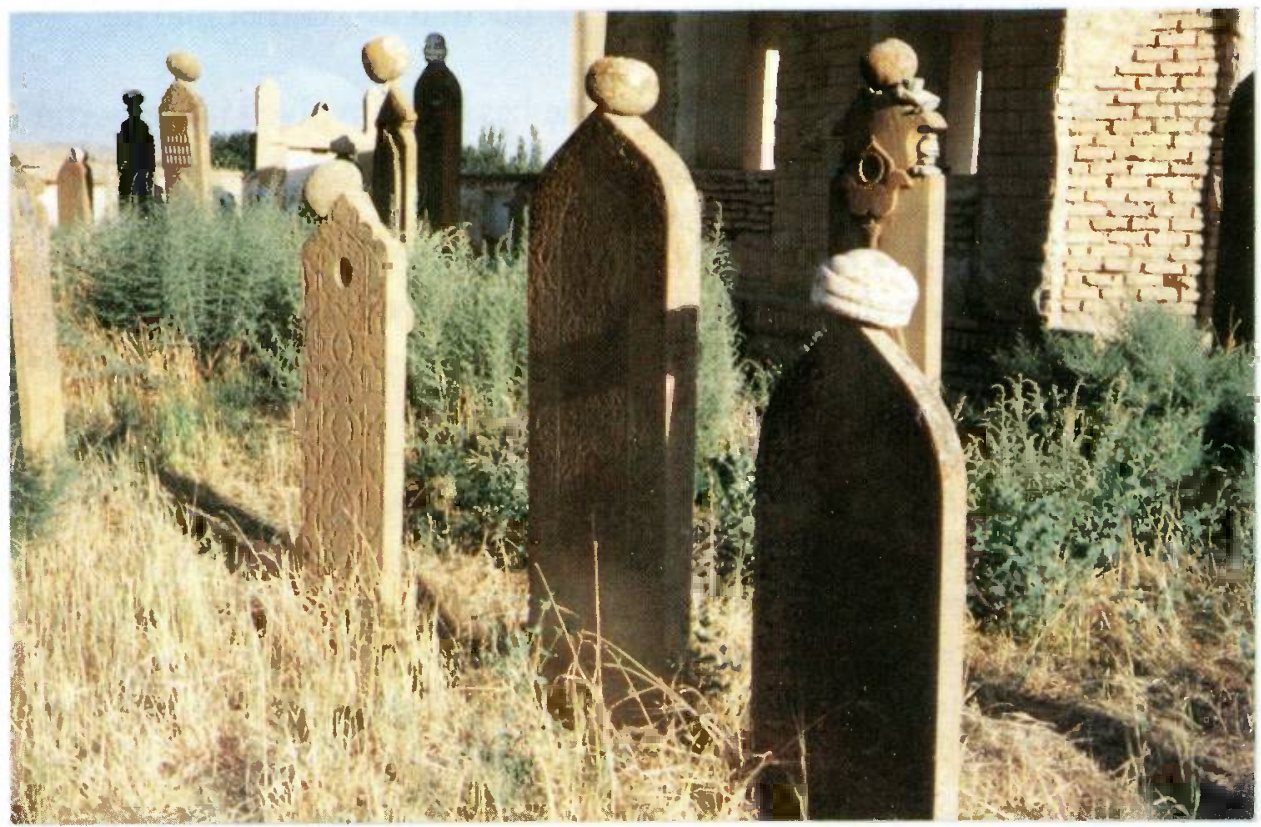




\section{GLOSSARY}

ACBAR - Agency Co-ordinating Body for Afghan Relief - Peshawar based body co-ordinating activities of national and international NGOs

BHC - Benzene HexaChloride, a persistent organo-chlorine insecticide "related" to DDT

CIMMYT - the International Maize and Wheat Improvement Centre, Mexico

DAP - Di-Ammonium Phosphate, a Phosphatic fertiliser

DDT - DichloroDiphenylTrichloroethane - a persistent organo-chlorine insecticide which accumulates in animal fatty tissues and enters the food chain causing a number of undesired environmental effects, most notably the demise of populations of many exotic birds of prey between 1945 and 1960 opening up the "environmental" debate.

F-1 - the first generation

FAO - Food and Agriculture Organisation of the United Nations

FFS - Farmers Field School - an integral part of the participatory approach in which technical information is transferred to farmers whereby farmers learn by "doing" in their own fields and by demonstration identifying the solutions to their own problems.

FOOD-FOR-SEED - arrangement between WFP and FAO to substitute cash payments with food grain in exchanges for wheat seed produced by contracted seed growers

FOOD-FOR-WORK - arrangement between WFP and other agencies to support sub-projects and programmes by paying for labour with food grain

HA - one hectare 10,000 square metres

ICARDA - the International Centre for Research into Arid Agriculture, Aleppo, Syria

IIBC - Commonwealth Agriculture Bureaux International Institute of Biological Control

IPGRI - International Plant Genetic Resource Institute, Rome, Italy

IPM - Integrated Pest Management - a farmer and environmentally friendly plant protection ideology, developed in the wake of the realisation that the use of pesticides actually created pest problems

IPP - Integrated Production and Protection. IPM to which production techniques have also been included. A holistic ideology for crop production.

IRRI - International Rice Research Institute, Los Banos, Philippines

ISE - Improved Seed Enterprise - parastatal formerly Afghan Seed Company attached to the ministry of agriculture

NGO - Non-Government Organisation, supposedly non-profit making "implementing partners", used by UN agencies to implement sub-projects and programmes

NPPP - National Professional Project Personnel

O-P - Organo-Phosphate. A group of insecticides with general broad-spectrum activity.

PPQD - Plant Protection and Quarantine Department of the ministry of agriculture, used in the northern provinces to implement plant protection sub-projects and programmes

SIDA - Department of Overseas Aid of the Government of Sweden

STA - Senior Technical Adviser

TONNE - a metric ton, $1000 \mathrm{~kg}$ or 2,205 pounds

ULV - Ultra Low Volume. A spray application technology that uses very small droplets and

relies on drift to apply about one litre of concentrated pesticide formulation per hectare

particularly well adapted for aerial and ground application against locusts.

UN - United Nations

UNDCP - United Nations Drug Control Programme

UNDP - United Nations Development Programme

UNHCR - United Nations High Commissioner for Refugees

UNOCHA - United Nations Organisation for the Co-ordination of Humanitarian Assistance to Afghanistan

WFP - World Food Programme of the United Naticirs

WHO - World Health Organisation of the United Nations 


\section{Food and Agriculture Organisation} of the United Nations

Produced by the Islamabad office of the FAO programme AFG/94/002

Integrated crop and food production in Afghanistan

Islamabad Office:

F-6/1, Street 45 , House 7

Tel: (051) 828217; 828218; 826434

Fax: (051) 826439

e-mail:afg94002@faopak.msm.cgnet.com

Postal Address:

c/o FAOR

PO Box 1476

Islamabad

Pakistan 